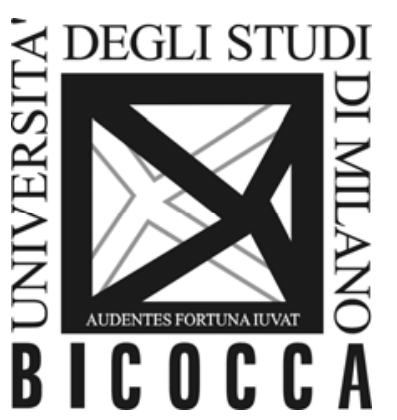

\author{
DEPARTMENT OF ECONOMICS, \\ MANAGEMENT AND STATISTICS \\ UNIVERSITY OF MILAN - BICOCCA
}

DEMS WORKING PAPER SERIES

\title{
Financial deepening and income distribution inequality in the euro area
}

Donatella Baiardi and Claudio Morana No.316 - November 2015

Dipartimento di Economia, Metodi Quantitativi e Strategie di Impresa

Università degli Studi di Milano - Bicocca

http://dems.unimib.it/ 


\title{
Financial deepening and income distribution inequality in the euro area*
}

\author{
Donatella Baiardi ${ }^{+}$and Claudio Morana ${ }^{\circledR \dagger}$ \\ ${ }^{+}$Università di Milano Bicocca (Milano, Italy) \\ ${ }^{\circledR}$ Università di Milano Bicocca (Milano, Italy), CeRP-Collegio Carlo Alberto \\ (Moncalieri, Italy) and Rimini Centre for Economic Analysis (Rimini, Italy).
}

November 2015

\begin{abstract}
The paper introduces a new specification of the Kuznets curve, where turning point per capita income is conditioned to the level of financial development. Within the proposed framework, it then provides new evidence on real income convergence for the euro area (EA) since the mid-1980s, with a special focus on the subprime and sovereign debt financial crises. We find strong empirical evidence in favor of an EA-wide steady-state financial Kuznets curve and of ongoing convergence across EA members toward a common per capita income turning point level. By means of a counterfactual analysis, we then detect a worsening in income inequality for all the EA countries during the financial crises, and not only for the peripheral countries, which were most strongly hit. From a policy perspective, our findings highlight the role of financial stability in fostering not only economic growth, but also to achieve a more even distribution of income.
\end{abstract}

Keywords: Euro area; financial development; financial stability; income distribution inequality; Kuznets curve; real convergence; subprime mortgage and sovereign debt crisis.

JEL classification: G20, G28, O11, O15, O16.

${ }^{*}$ This project has received funding from the European Union's Seventh Framework Programme for research, technological development and demonstration under grant agreement no. 3202782013-2015. A previous version of this paper was presented at the Second Conference of the Society for Economic Measurement. The authors are grateful to participants for constructive comments.

${ }^{\dagger}$ Address for correspondence: Claudio Morana, Università di Milano-Bicocca, Dipartimento di Economia, Metodi Quantitativi e Strategie di Impresa, Piazza dell'Ateneo Nuovo 1, 20126, Milano, Italy. E-mail: claudio.morana@unimib.it. 


\section{Introduction}

Eight years after the burst of the subprime financial crisis in August 2007, the euro area (EA) economy has not yet fully recovered from the ensuing Great Recession and sovereign debt crisis, which have severely affected across- and within-country convergence as well. Following the crisis, across-country real convergence has in fact turned into divergence, as imbalances between Northern and Southern EA country blocks have so far been absorbed mostly through fiscal austerity and internal devaluation in the peripheral countries, rather than through external adjustment (Bagliano and Morana, 2011; Gros, 2013; De Grauwe, 2015). Within-country income divergence has also sizably deepened, EA income inequality having increased about $2.5 \%$ on average over the period 2008 through 2013, and reached historical peak levels: the average income ratio of the richest to poorest $10 \%$ of population is currently 10:1 for EA and other OECD countries, 30\% larger than it was in the early 1980s (OECD, 2013; OECD, 2014a). Since the financial crisis and ensuing austerity measures have reduced EA population wealth (through the contraction of housing prices) and negatively affected labor market prospects (due to the large and persistent raise in unemployment), higher income divergence might then turn out to be long lasting (see also Bertola, 2013; D'Errico et al., 2015).

The above evidence is at first sight consistent with a negative linkage between financial deepening and income distribution, i.e., excessive financialization being detrimental to growth (Borio and Lowe, 2004; Arcand et al., 2015), as also found by various within analyses and pooled dynamic panel data studies within a short-term perspective (Jaumotte et al., 2008; Jauch and Watzka, 2012; Rodriguez-Pose and Tselios, 2009; Roine et al., 2009; Gimet and Lagoarde-Segot, 2011). ${ }^{1}$

However, it is in contrast with recent interpretations of the linkage between inequality and economic development posited by the Kuznets (1955) curve, explaining its inverse-U shape as arising from the adoption of new technologies, shifting the economy from an unsophisticated to a modern financial system, strictly dependent on banking activities and stock markets (Greenwood and Jovanovic, 1990; Barro, 2000; Aghion and Howitt, 1997). In this framework, financial development leads to a more even distribution of income by allowing access to finance to a larger population share (Greenwood and Jovanovic, 1990; Smith, 2003; Deidda, 2006; Townsend and Ueda, 2006; Kim and Lin, 2011) $)^{2}$, as well as by fostering economic growth through improved physical and human capital accumulation and technological innovation (Smith, 2003; Beck et al., 2000). Due to informational asymmetries, technological progress and financial innovations could be even more strictly interwoven, the former making existing screening tools eventually outdated, in turn requiring financial innovation to maintain effective the selection of profitable investment projects, economic growth and an even distribution of income (Laeven et al., 2015). Empirical support for the latter long-term perspective is in general found by cross-sectional (between) analyses or panel data studies using multi-year averaging to control for business cycle effects (Beck et al., 2007; Kappel, 2010; Li et al., 1998; Clarke et al., 2006). An inverse-U shaped relationship, i.e., financial development leading to a contraction in income inequality once a threshold level is achieved, as well as asymmetric effects, i.e., financial deepening decreasing inequality more strongly for high- than low-income countries, have also been documented in the literature (Kim and Lin, 2011; Kappel, 2010).

In the light of the overall thin and conflicting available empirical evidence, the paper then

\footnotetext{
${ }^{1}$ Transitory, negative effects on the wage share of positive stock market shocks have also been documented (Beltratti and Morana, 2007).

${ }^{2}$ As financial intermediation is costly, in an unsophisticated financial system only the rich initially benefit from better financial markets, the poor having to rely on informal, family connections for funding. Yet, once the diffusion of financial intermediation throughout society has sufficiently progressed, financial deepening leads to a more even distribution of income by lowering information and transactions costs, and allowing access to financial service to agents (small firm; the poor) who, due to lack of collateral and credit histories, are severely constrained by inherited wealth.
} 
further assesses the role of financial deepening in EA income distribution developments since the mid-1980s, innovating the literature along different perspectives. Firstly, it proposes a new specification of the Kuznets curve (KC), by conditioning its turning point per capita income to the level of financial development. Within this framework, financial development then contributes to a more even distribution of income by lowering the turning point per capita income level. As it allows to jointly test for the traditional inverse-U shaped linkage between economic development and income inequality, as well as an inverse relationship between financial development and the KC turning point, comparison of the new financial Kuznets curve (FKC) with the existing literature is straightforward. Yet, a caveat applies, as in previous contributions financial deepening enters the KC specification at most as an ancillary variable (Lee, 2006; Barrios and Strobl, 2009; Beck et al., 2007; Rodrıguez-Pose and Tselios, 2009; Roine et al., 2009; Jauch and Watzka, 2012).

Secondly, our empirical analysis is focused on real income convergence for the current 19 EA member states, i.e., Austria, Belgium, Cyprus, Estonia, Finland, France, Germany, Greece, Ireland, Italy, Latvia, Lithuania, Luxemburg, Malta, the Netherlands, Portugal, Slovakia, Slovenia and Spain, over the period 1985 through 2013. By covering the most relevant events in the European Monetary System and Union history, such as the removal of all the restrictions to capital movements between member states in 1990, the EMS crisis in 1992 and 1993, the introduction of the Maastricht Treaty in 1993 and the Stability Pact in 1997, the introduction of the Euro in 1999, the subprime financial crisis in 2007 and ensuing Great Recession, as well as the EA sovereign debt crisis in 2010, the assessed sample is highly informative concerning the various dimensions through which financial deepening and income inequality might be interrelated. Actually, at our knowledge, the subprime plus sovereign debt crisis period has not yet entirely investigated in the financial development-income inequality literature, the most updated available study, i.e., Jauch and Watza (2012), considering a sample ending in 2008.

Finally, also novel is the econometric framework employed for the analysis, as a new Frequentist model averaging estimation strategy (Morana, 2015) is implemented. By jointly exploiting all the information available in various proxy variables for financial deepening and income inequality, and relying on more degrees of freedom, the employed method yields robust, consistent and relatively more efficient estimation than available competing econometric approaches, granting an accurate assessment of the linkages of interest.

To preview the results of the papers, we find strong empirical evidence in favor of an EAwide steady-state financial Kuznets curve, i.e., of a long-term, inverse-U shaped linkage between income inequality and economic development, where financial deepening contributes to a more even distribution of income by lowering the turning point per capita income level. We interpret the finding also as evidence of ongoing across-country convergence toward a common turning point real per capita income level, estimated at about $€ 13.000$ (year 2005 prices). In the light of the financial gap dividing more and less developed EA members, a sizable $20 \%$ contraction in the turning point income level might then be achieved, through further financial development, by Cyprus, Estonia, Latvia, Lithuania, Malta, Slovakia and Slovenia. Also sizable would be the associated reduction in income inequality for the latter countries, particularly when assessed at market income.

While the financial crisis would have not undermined the validity of the EA-wide steadystate FKC, as an inverse linkage between inequality and economic development still holds also during the 2008-2013 period, it has however sizably increased income inequality for all EA member countries. In fact, by means of a counterfactual analysis, we find higher inequality than it would have otherwise occurred in a non-crisis scenario, not only for the countries that were most severely hit by the crisis, i.e., Cyprus, Greece, Ireland, Italy, Portugal and Spain, but also for other core EA countries, likewise Austria, Belgium, Finland, France, Germany and Luxemburg. A too much finance phenomenon is also detected during the crisis, inequality falling as financial deepening increases up to a threshold value of 90-100 GDP points, to then 
rise thereafter; coherently, the countries that were most affected by the sovereign debt crisis show the highest figures for both variables.

The rest of the paper is as follows. Sections 2 deals with the specification and estimation of the financial Kuznets curve, while Sections 3 and 4 present data and estimation results. Empirical properties of the EA FKCs and convergence issues are then discussed in Section 5, while the implications of the recent financial crises for income distribution are investigated in Section 6. Finally, conclusions and policy recommendations are reported in Section 7.

\section{Specification and estimation of the financial Kuznets curve}

\subsection{The financial Kuznets curve}

Consider the model

$$
y_{n}=a_{n}+b x_{n}+c x_{n}^{2}
$$

where $n$ refer to the $n$-th country, $n=1, \ldots, N, y_{n}$ is a measure of income inequality, i.e., the Gini Index, $x_{n}$ is a wealth/economic development indicator, i.e., the real per capita income/GDP level, $a_{n}$ is a country-fixed effect. Coefficients $b$ and $c$ obey the restrictions $b>0$ and $c<0$, in order (1) to be consistent with the inverse-U shaped relationship posited by Kuznets (1955).

The KC turning point $\left(x_{n}^{\star}\right)$ can then be obtained by maximizing (1) with respect to $x_{n}$, yielding

$$
x_{n}^{\star}=-\frac{b}{2 c} .
$$

Following Bradford et al. (2005), by differentiating (1) with respect to time and substituting (2) it is obtained

$$
\begin{aligned}
\frac{\partial y_{n}}{\partial t} & =\left(b+2 c x_{n}\right) \frac{\partial x_{n}}{\partial t} \\
& =\alpha\left(x_{n}-x_{n}{ }^{\star}\right) g_{n}
\end{aligned}
$$

where $\alpha \equiv 2 c<0$ and $g_{n} \equiv \frac{\partial x_{n}}{\partial t}$ is the (per capita) income growth rate in each country.

The instantaneous change in economic inequality then depends on the per capita income growth rate $g_{n}$ and on the distance of $x_{n}$ from its turning point $x_{n}{ }^{\star}$; moreover, assuming $g_{n}>0$, inequality increases when $x_{n}<x_{n}{ }^{\star}$ and decreases when $x_{n}>x_{n}{ }^{\star}$.

By conditioning the turning point per capita income in (2) to the level of financial development $\left(f_{n}\right)$, i.e.,

$$
x_{n}^{\star}=\lambda_{0}+\lambda_{1} f_{n}
$$

and substituting (4) in (3), one has

$$
\frac{\partial y_{n}}{\partial t}=\beta_{0}\left[x_{n}-\left(\lambda_{0}+\lambda_{1} f_{n}\right)\right] g_{n}
$$

where $\lambda_{0}$ and $\lambda_{1}$ are parameters, with $\lambda_{1}<0$, implying that a country with more developed financial markets reaches the $\mathrm{KC}$ turning point at a relatively lower income level than a country with a less developed financial system.

\subsection{Econometric specification}

The econometric specifications used in our empirical analysis are then derived by integrating (5) over time.

In particular, the linear cross-sectional specification is

$$
y_{n}=\mu+\beta_{0}\left(x_{n} g_{n}\right)+\beta_{1} g_{n}+\beta_{2}\left(f_{n} g_{n}\right)+\boldsymbol{\delta}^{\prime} \mathbf{z}_{n}+\varepsilon_{n}, \quad n=1, \ldots, N
$$


where $\mu$ is the intercept, $\beta_{0} \equiv 2 \alpha<0$, as required by the inverse relationship between income inequality and the level of economic development posited by the $\mathrm{KC} ; \beta_{2} \equiv-\beta_{0} \lambda_{1}<0$, consistent with the hypothesis of an inverse relationship between financial development and the turning point of the KC, while $\beta_{1}$ can take either positive or negative values, as well as the $k \times 1$ vector of parameters $\boldsymbol{\delta}$ corresponding to the $k$ control variables $\mathbf{z}_{n}$; finally $\varepsilon_{n}$ is a zero mean i.i.d. error term.

A log-log specification is also employed, i.e.,

$$
\ln y_{n}=\mu+\beta_{0}\left(\ln x_{n} g_{n}\right)+\beta_{1} g_{n}+\beta_{2}\left(\ln f_{n} g_{n}\right)+\boldsymbol{\delta}^{\prime} \ln \mathbf{z}_{n}+\varepsilon_{n}, \quad n=1, \ldots, N .
$$

From the coefficients $\beta_{0}, \beta_{1}$ and $\beta_{2}$, the structural parameters of interest $\lambda_{0}$ and $\lambda_{1}$ can then be obtained as $\lambda_{0} \equiv-\frac{\beta_{1}}{\beta_{0}}$ and $\lambda_{1} \equiv-\frac{\beta_{2}}{\beta_{0}}<0$.

\subsection{Estimation}

Neither income inequality nor financial development are uniquely measured. For instance, income inequality can be measured by the market or net income Gini Index or various top/bottom income distribution quantile ratios; financial development can be measured by the GDP shares of credit to the private sector, liquid liabilities, or stock market capitalization. The selection of a single proxy variable for income inequality and financial development might then be arbitrary and lead to non robust results, also in the light of the small cross-sectional dimension available (19 countries/observations).

In order to deal with the above drawback, in the paper we have then implemented model averaging by stacking estimation (M.A.S.; Morana, 2015). Relatively to alternative approaches, M.A.S. has the advantage of performing model averaging ex-ante in a single step, optimally selecting model's weight according to the MSE metric; moreover, it is straightforward to implement, only requiring the estimation of a single augmented regression. By jointly exploiting ex-ante all the information available and benefiting of more degrees of freedom, the proposed approach yields robust, consistent and (relatively) more efficient estimation than available ex-post methods.

Hence, consider the regression function

$$
\mathbf{y}=\mathbf{X} \boldsymbol{\beta}+\varepsilon
$$

and suppose that $P$ candidate dependent variables $\mathbf{y}$ are available, i.e., $\mathbf{y}_{1}, \mathbf{y}_{2}, \ldots, \mathbf{y}_{P}$, where $\mathbf{y}_{p}, p=1, . ., P$, is a $N \times 1$ column vector of observations, as well as $R$ candidates for one of the $K$ regressors in the model, ordered first for simplicity, i.e., $\mathbf{x}_{1 r}, r=1, \ldots, R$, yielding up to $R$ candidate design matrices $\mathbf{X}_{r}$ for $\mathbf{X}{ }^{3}$ Moreover, the usual properties of the classical linear regression function (asymptotic case) are assumed to hold.

In principle, up to $P \times R$ alternative disjoint models could be estimated and then averaged

\footnotetext{
${ }^{3}$ In our application, $P=R=3$, as three measures of income inequality $\mathbf{y}_{p}$, as well as three measures of financial deepening $\mathbf{x}_{1 r}$, are employed, yielding therefore up to $P \times R=9$ alternative regression models.
} 
ex-post, i.e.,

$$
\begin{aligned}
\mathbf{y}_{1}= & \mathbf{X}_{1} \boldsymbol{\beta}+\varepsilon_{1,1} \\
\mathbf{y}_{1}= & \mathbf{X}_{2} \boldsymbol{\beta}+\varepsilon_{1,2} \\
& \vdots \\
\mathbf{y}_{1}= & \mathbf{X}_{R} \boldsymbol{\beta}+\varepsilon_{1, R} \\
& \vdots \\
\mathbf{y}_{P}= & \mathbf{X}_{1} \boldsymbol{\beta}+\varepsilon_{P, 1} \\
\mathbf{y}_{P}= & \mathbf{X}_{2} \boldsymbol{\beta}+\varepsilon_{P, 2} \\
& \vdots \\
\mathbf{y}_{P}= & \mathbf{X}_{R} \boldsymbol{\beta}+\varepsilon_{P, R} .
\end{aligned}
$$

Their union yields the stacked model

$$
\mathbf{y}_{\mathbf{P}, \mathbf{R}}=\mathbf{X}_{\mathbf{P}, \mathbf{R}} \boldsymbol{\beta}+\varepsilon_{\mathbf{P}, \mathbf{R}}
$$

where $\boldsymbol{\beta}$ is the $K \times 1$ vector of parameters, $\mathbf{y}_{\mathbf{P}, \mathbf{R}}=\operatorname{vec}\left(\mathbf{i}_{R} \otimes\left[\begin{array}{llll}\mathbf{y}_{1} & \mathbf{y}_{2} & \ldots & \mathbf{y}_{P}\end{array}\right]\right)$ is the $(N \times P \times R) \times 1$ vector collecting the $P \mathbf{y}_{p}(N \times 1)$ vectors, $p=1, . ., P$, which are then stacked on top of one other $R$ times, vec is the vectorization operator, $\otimes$ is the Kronecker product and $\mathbf{i}_{R}$ a $R \times 1$ unitary vector. ${ }^{4}$

By denoting $\mathbf{X}_{*}=\left[\begin{array}{llll}\mathbf{X}_{1}^{\prime} & \mathbf{X}_{2}^{\prime} & \ldots & \mathbf{X}_{R}^{\prime}\end{array}\right]^{\prime}$ the $(R \times N) \times K$ matrix obtained by stacking the $R$ candidate design matrices on top of one another, $\mathbf{X}_{\mathbf{P}, \mathbf{R}}$ is then the $(P \times R \times N) \times K$ design matrix yield by staking $P$ times the matrix $\mathbf{X}_{*}$ on top of itself, i.e., $\mathbf{X}_{\mathbf{P}, \mathbf{R}}=\left[\begin{array}{llll}\mathbf{X}_{*}^{\prime} & \mathbf{X}_{*}^{\prime} & \ldots & \mathbf{X}_{*}^{\prime}\end{array}\right]^{\prime}$. Finally, $\boldsymbol{\varepsilon}_{\mathbf{P}, \mathbf{R}}=\left[\begin{array}{lllllll}\varepsilon_{1,1}^{\prime} & \ldots & \varepsilon_{1, R}^{\prime} & \ldots & \varepsilon_{P, 1}^{\prime} & \ldots & \varepsilon_{P, R}^{\prime}\end{array}\right]^{\prime}$ is a $(P \times R \times N) \times 1$ vector of residuals. Hence, the sample size of the stacked model is $S=N \times P \times R$.

The stacked $O L S$ estimator is then computed as

$$
\begin{gathered}
\hat{\boldsymbol{\beta}}_{e a}=\left(\mathbf{X}_{\mathbf{P}, \mathbf{R}}^{\prime} \mathbf{X}_{\mathbf{P}, \mathbf{R}}\right)^{-1} \mathbf{X}_{\mathbf{P}, \mathbf{R}}^{\prime} \mathbf{Y}_{\mathbf{P}, \mathbf{R}} \\
\tilde{\sigma}_{e a}^{2}=\frac{\hat{\varepsilon}_{\mathbf{P}, \mathbf{R}}^{\prime} \hat{\varepsilon}_{\mathbf{P}, \mathbf{R}}}{S} .
\end{gathered}
$$

Moreover

$$
\sqrt{S}\left(\hat{\boldsymbol{\beta}}_{e a}-\boldsymbol{\beta}\right) \stackrel{d}{\rightarrow} N\left(\mathbf{0}, \sigma^{2} \operatorname{plim}\left(S^{-1} \mathbf{X}_{\mathbf{P}, \mathbf{G}}^{\prime} \mathbf{X}_{\mathbf{P}, \mathbf{G}}\right)^{-1}\right)
$$

and therefore

$$
\hat{\boldsymbol{\beta}}_{e a} \stackrel{a s y}{\sim} N\left(\boldsymbol{\beta}, \sigma^{2}\left(\mathbf{X}_{\mathbf{P}, \mathbf{G}}^{\prime} \mathbf{X}_{\mathbf{P}, \mathbf{G}}\right)^{-1}\right) .
$$

As shown by Morana (2015), the stacked $O L S$ estimator in (11) and (12) can be stated as

$$
\begin{gathered}
\hat{\boldsymbol{\beta}}_{e a}=\sum_{r=1}^{G} \check{\mathbf{W}}_{r}^{*}\left(\frac{1}{P} \sum_{p=1}^{P} \hat{\boldsymbol{\beta}}_{p, r}\right) \\
\tilde{\sigma}_{e a}^{2}=\frac{1}{G} \sum_{r=1}^{G} \frac{1}{P} \sum_{p=1}^{P} \tilde{\sigma}_{p, r}^{2}
\end{gathered}
$$

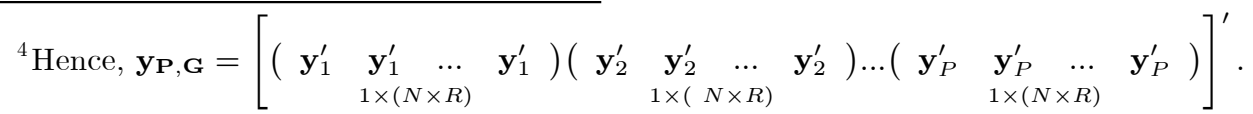


where $\sum_{r=1}^{G} \check{\mathbf{W}}_{r}^{*}=\sum_{r=1}^{G}\left[\mathbf{X}_{r}^{\prime} \mathbf{X}_{r}+\mathbf{K}_{r}\right]^{-1}\left(\mathbf{X}_{r}^{\prime} \mathbf{X}_{r}\right)=\mathbf{I}_{K}, \hat{\boldsymbol{\beta}}_{p, r}=\left(\mathbf{X}_{r}^{\prime} \mathbf{X}_{r}\right)^{-1} \mathbf{X}_{r}^{\prime} \mathbf{y}_{p}$ and $\tilde{\sigma}_{p, r}^{2}=\frac{\hat{\boldsymbol{\varepsilon}}_{p, r}^{\prime} \hat{\boldsymbol{\varepsilon}}_{p, r}}{T}$. The MSE-optimal ex-ante weights, contained in the $K \times K$ matrices $\check{\mathbf{W}}_{r}^{*}, r=1, \ldots, R$, are then computed by taking into account all the information available on the various candidate regressors and are proportional to their relative variation. Ex-ante model averaging estimation of the slope vector $\hat{\boldsymbol{\beta}}_{e a}$ is then computed across all the possible $P \times R$ disjoint estimators $\hat{\boldsymbol{\beta}}_{p, r}$. Similarly for ex-ante model averaging estimation of the variance $\tilde{\sigma}_{e a}^{2}$, which is equivalent to the arithmetic average of all the $P \times R$ disjoint estimators $\tilde{\sigma}_{p, r}^{2}$. In contrast to ex-post model averaging, which would be implemented through a multi-step procedure, requiring the estimation of all the $P \times R$ alternative models, yet without granting the use of MSE-optimal weights, the M.A.S. estimator in (11) and (12) yields MSE-optimal model averaging, ex-ante, in a single step. Extension to GMM estimation, considered in this paper as well, is straightforward, requiring coherent stacking of the instruments. See Morana (2015) for details, also for the case of violation of the hypothesis of conditional homoskedasticity.

\section{The data}

The dataset is an unbalanced panel of annual observations for the 19 current euro area member countries, covering the period 1985 through $2013(N=19$ and $T=28)$, i.e., Austria, Belgium, Cyprus, Estonia, Finland, France, Germany, Greece, Ireland, Italy, Latvia, Lithuania, Luxemburg, Malta, the Netherlands, Portugal, Slovakia, Slovenia and Spain. ${ }^{5}$

Income inequality $(y)$ is measured by means of the market $(G M)$ and net income $(G N)$ Gini Index, computed by using household market and disposable income (post-tax, post-transfer), respectively, as reported in the Standardized World Income Inequality Database (SWIID). In the light of its wide use in the empirical literature, the net income Gini Index $(G W)$, reported in the World Income Inequality Database (WIID), is also employed in the analysis. The latter are then stacked to yield a single inequality indicator.

The level of economic development is measured by real per capita GDP $(x)$ at year 2005 constant prices. Moreover, three distinct proxies for financial development $(f)$ are employed, i.e., the GDP shares of credit to the private sector $(c)$, of liquid liabilities $(m)$ and of stock market capitalization $(s)$. These variables have been widely employed as alternative measures of financial depth in the literature; rather we use them simultaneously, by stacking the three indicators in a single variable, as for the Gini Index.

Furthermore, in order to account for the influence of factors other than economic growth and financial development on income inequality, different control variables are included, i.e., the age dependency ratio $(D E P)$; the GDP share of government spending $(P E)$, the spread between the interest rate on 10-year government bonds relatively to interest rate paid on 10-year German Treasury bonds $(S P R)$; globalization/trade openness $(T R D)$, as measured by the GDP share of exports plus imports; the population share living in urban areas $(U R B)$. Coherent with available theoretical and empirical results, we expect an increase in $P E, S P R$ and $U R B$ to lead to a more even distribution of income, while an increase in $D E P$ and $T R D$ to a worsening in income equality.

Due to stationarity properties, sample averages for the Gini Index $(G M, G N, G W)$ and control variables are employed for estimation of (6) and (7), while variables $x, c, m$ and $s$ are measured at mid-sample (year 2000) trend values, and $g$ is the average growth rate of trend real per capita income $(x)$. These transformations of the original series allow to cast the analysis within a long-term perspective as in Bradford et al. (2005). Having filtered out short-lived fluctuations, potentially related to various forms of instability, the data employed in

\footnotetext{
${ }^{5}$ For Slovakia, Slovenia, Estonia and Lithuania a smaller data set is available, observations starting in 1992, 1995, 1995 and 1991, respectively.
} 
the analysis are then coherent with a framework where financial development is associated with prevailing economic and financial stability. See the Appendix for details on the data employed in the study.

\section{Empirical results}

The results of the estimated cross-sectional regressions, performed using standardized data, are reported in Tables 1 and 2 for the linear and log-log specifications, respectively. Different models, obtained by varying the set of included control variables $(D E P, P E, S P R, T R D$, $U R B$ ), are estimated (columns 1-4 in each tables). Heteroskedasticity consistent standard errors are reported in all cases.

As shown in the Tables, parameter estimates are consistent with the underlying theoretical framework, pointing to an inverse-U shaped linkage between inequality and the level of economic development ( $\beta_{0}$ parameter) and an inverse linkage between the turning point per capita income level and financial deepening ( $\beta_{2}$ parameter). In particular, concerning the KC hypothesis, the estimated $\beta_{0}$ parameter is, as expected, negative and statistically significant for both the linear and log-log specifications, equal to -0.329 and -0.274 , respectively, for our preferred models, selected according to statistical significance and explanatory power (column 4, Table 1; column 2, Table 2). Moreover, the inverse relationship between the KC turning point per capita income level and the level of financial development is also clear-cut, as the estimated $\beta_{2}$ parameter is negative and statistically significant across specifications, equal to -0.337 and -0.243 , for the selected linear and log-log models, respectively.

Coherently, $O L S$ estimates of the structural parameter of interest $\lambda_{1} \equiv-\frac{\beta_{2}}{\beta_{0}}$ are, as expected, negative in sign, about -1.024 and -0.887 for the selected linear and log-log models, respectively. Financial development would then contribute to a more even distribution of income, by progressively lowering the EA-wide KC turning point per capita income level; we interpret the latter finding also as evidence of ongoing convergence across EA member states, toward a common KC turning point per capita income level.

The findings are robust to specification choices in terms of control variables. In fact, while point estimates for $\beta_{0}$ and $\beta_{2}$ somewhat differ across models, particularly when columns 1 and 2 are compared with columns 3 and 4, a Bonferroni bounds test (not reported), carried out considering the six different combinations of the available four models, does not allow to reject, even at the $20 \%$ significance level, the null of equal coefficients across models, for both parameters. ${ }^{6}$

On the other hand, point estimates of $\beta_{1}$ sizably differs across models, i.e., -0.220 and -0.070 for the selected linear and log-log models, respectively, yielding $O L S$ estimates of the structural parameter $\lambda_{0} \equiv-\frac{\beta_{1}}{\beta_{0}}$ equal to -0.669 and -0.225 , respectively.

Finally, concerning control variables, differences can be noted between the linear and log-log models. In fact, while all the control variables are significant for the linear model, only $D E P$, $P E$ and $S P R$ have been retained in the log-log specification, the inclusion of $U R B$ and TRD then possibly controlling for features (nonlinearity) neglected in the linear model, yet accounted by the log-log model. In all cases, however, signs are consistent with expectations, as an increase in $P E, S P R$ and in $U R B$ leads to a more even distribution of income, while an increase in $D E P$ and $T R D$ to a worsening in income equality.

\footnotetext{
${ }^{6}$ In fact, concerning $\beta_{0}$, the minimum p-value of the test are 0.052 for the linear model and 0.399 for the $\log -\log$ model, to be compared with a threshold p-value equal to 0.033 in both cases. Moreover, concerning $\beta_{2}$, values are 0.454 and 0.633 , respectively, still to be compared with a 0.033 threshold value.
} 


\subsection{Robustness analysis I: GMM estimation}

The aim of GMM analysis is controlling for the potential endogeneity of the level of financial development in (6) and (7). Indeed, our specification is coherent with the supply-lead view, positing financial deepening to be causal for economic growth and, hence, for income distribution. While the supply-lead view appears to be empirically well grounded (see Demirgüç-Kunt and Levine, 2008), other theoretical underpinnings of the linkage between financialization, economic growth and inequality have however been put forward in the literature. The demand-following hypothesis, for instance, posits a minor role for finance in economic growth, financial development actually being a consequence of economic growth, rather then one of its engines (Patrick, 1966; Lucas, 1988; Chandavarkar, 1992). Moreover, in the light of Greenwood and Jovanovic (1990), Bangake and Eggoh (2011), and, more recently, of Laeven et al. (2015), feedback effects between growth, inequality and financial development might also be empirically relevant.

Consistent with the available literature, the regressor of interest, $f g$, is instrumented using the legal origin dummy variables suggested by La Porta et al. (LO; 1997). The latter are related to the geographical origin of the legal framework, which can be connected with four main traditions, i.e., English, French, German and Scandinavian. Being predetermined and containing information on the degree of enforceability of financial contracts, $L O$ have been proved to be valid instruments (see, among others, Levine et al., 2000; Laeven et al., 2015). ${ }^{7}$

In particular, in the empirical analysis we have jointly employed two sets of instruments: the former composed of the four legal origin dummy variables themselves $(L O)$; the latter of the legal origin dummy variables interacted with the rate of growth of per capita income $(L O \times g)$. Due to the inclusion of the intercept in the model, only three instruments out of four, for each group, i.e., a total of six instruments, have been used for $G M M$ estimation.

The validity of $O L S$ estimation has then been assessed by means of a Haussman test (Exogeneity), comparing $O L S$ and GMM estimates of the parameter $\beta_{2}$. As shown in Tables 1-2 (column 5), the (heteroskedasticity-robust) Exogeneity test points to valid OLS estimation for both the linear and log-log models, as the null hypothesis of consistent $O L S$ estimation (weak exogeneity of $f g$ ) is never rejected, at the $1 \%$ level for the linear model and at a much larger level for the log-log model (22\%). Somewhat conflicting results are yield by the Hansen-J statistic, rejecting the null hypothesis of instruments uncorrelated with the structural equation residuals, and the Kleibergen-Paap rk test (Underidentification), properly rejecting the null hypothesis of uncorrelated instruments with the suspected endogenous variable $f g$.

In the light of the above conflicting evidence, following Lewbel (2012), GMM estimation has been repeated using generated instruments, constructed from the residuals of an auxiliary equation regressing $f g$ on all the exogenous variables, including the constant, multiplied by the same regressors (in deviation from the mean). The stronger the degree of scale heteroskedasticity in the structural residuals, the higher will be the correlation of the generated instruments with the included endogenous variables $f g$. Due to the presence of heteroskedastic errors, the latter generated instruments are then granted to be well behaved in our application.

In Tables 1-2 (columns 6-7) we then report the results of two additional GMM regressions, the former using only generated instruments, the latter supplementing legal origin dummy variables with generated regressors. As shown in the Tables, the estimated parameters are strongly robust to the employed instruments, which appear to be valid in all cases according to the Underidentification test, yet only for the log-log model (Table 2, column 6), according to the Hansen-J statistic. In the latter case, however, estimated parameters are virtually coincident with those obtained using La Porta (1997) instruments (column 5). Moreover, the Exogeneity

\footnotetext{
${ }^{7}$ The original dataset of La Porta et al. (1997) has been updated following The World Factbook List of Legal System, yielding the following four groups of countries. English tradition $\left(L O_{E}\right)$ : Ireland and Malta; French tradiation $\left(L O_{F}\right)$ : Belgium, Cyprus, France, Greece, Italy, Luxembourg, the Netherlands, Portugal, Spain; German tradition $\left(L O_{G}\right)$ : Austria, Estonia, Germany, Latvia, Slovakia and Slovenia; Scandinavian tradition $\left(L O_{S}\right)$ : Finland and Lithuania.
} 
test points to consistent $O L S$ estimation, at the $5 \%$ level, for both the linear and log-log models. Generated instruments $G M M$ also does not improve upon $O L S$ in terms of residual misspecification tests. Finally, $O L S$ and $G M M$ estimates are not statistically different (not reported), inviting the computation of an average $O L S$ and $G M M$ estimate as well, which is denoted $M I X{ }^{8}$

In the light of the above results, we then regard $O L S$ estimation of the structural parameters of interest to be valid and robust to endogeneity issues; moreover, the log-log model should be preferred to the linear specification.

\subsection{Robustness analysis II: disjoint estimation}

In the second exercise we assess the robustness of $O L S$ estimation of $\beta_{0}$ and $\beta_{2}$ to all the possible specification choices nested in the stacked regression model in (10), i.e., 15 alternative submodels in total. Of the latter, the first nine regressions correspond to the disjoint models obtained by regressing each of the three Gini indexes on each of three available indicators of financial development. In this case, the dependent variable $y$ would then be defined as $G N, G M$ and $G W$ in turn, while the variable $f$ as $c, m$ and $s$ in turn as well. Moreover, three additional regressions are yield by partially stacked models, where the stacked Gini index series GINI, composed of $G N, G M$ and $G W\left(G I N I=\left[\begin{array}{lll}G N^{\prime} & G M^{\prime} & G W^{\prime}\end{array}\right]^{\prime}\right)$, is regressed on each of the available three measures of financial development $c, m$ and $s$, in turn. Finally, three additional models are yield by other partially stacked models, where each Gini index, $G N, G M$ and $G W$, is regressed in turn on the stacked financial development indicator, composed of $c, m$ and $s$ $\left(f=\left[\begin{array}{lll}c^{\prime} & m^{\prime} & s^{\prime}\end{array}\right]^{\prime}\right)$.

Figure 1 reports boxplots for $O L S$ estimated $\beta_{0}$ and $\beta_{2}$ parameters, obtained from the stacked regression in (10) and its 15 nested submodels. ${ }^{9}$ As is shown in the plots, the negative linkage between income inequality and economic development $\left(\beta_{0}\right)$ posited by the Kuznets curve, as well as between the $\mathrm{KC}$ turning point per capita income and financial development $\left(\beta_{2}\right)$, is strongly robust across specifications. Coherent with yielding an average measure of the marginal effects of interest, stacked $O L S$ estimates fall within the interquantile range of the corresponding empirical distributions.

\section{Empirical properties of the financial Kuznets curve}

Two main conclusions can be drawn from the above empirical analysis; firstly, there is evidence of an inverse-U shaped relationship between inequality and economic development for the EA, showing income inequality decreasing as a certain threshold in economic development is passed; the latter threshold is inversely related to the degree of financial deepening, suggesting the definition of EA-wide steady-state financial Kuznets curve; secondly, and as a consequence, there is evidence of ongoing convergence across EA member countries toward a common turning point per capita income level, as determined by the progressive diffusion of financial development. ${ }^{10}$

\footnotetext{
${ }^{8}$ The $\mathrm{p}$-value of the test for the difference of the $\beta_{0}, \beta_{1}$, and $\beta_{2}$ parameters obtained from OLS and GMM estimation are, in fact, $0.864,0.898$ and 0.841 , respectively, for the linear model; $0.473,0.573$ and 0.315 , respectively, for the log-log model.

${ }^{9} \mathrm{~A}$ full set of results is available upon request from the authors.

${ }^{10}$ Coherent with empirical findings of the paper (see below) and the literature (Arcand et al. , 2015; Borio and Lowe, 2004), beyond a certain threshold value (80-100 GDP points) a too much finance effect can manifest, further financial deepening becoming detrimental to growth and inequality. The financial development threshold therefore implicitly defines the steady-state turning point per capita income level, toward which convergence would occur ceteris paribus. Financial deepening would then lead to economic expansion and lower turning point per capita income and inequality until the threshold is achieved (boom phase). Beyond the threshold, further financial deepening leads to economic contraction and lower turning point per capita income and inequality (boost phase).
} 
In this Section we provide further details on both issues. See the Appendix for technical details concerning computations below.

\subsection{EA-wide steady-state FKC properties}

On the basis of the estimated structural parameters $\lambda_{0}$ and $\lambda_{1}$, the turning point of the EAwide steady-state FKC (SS-FKC) is computed using (4). As shown in Table 3, the estimated turning point $\left(\hat{x}^{*}\right)$ is strongly robust to the method employed, in the range $€ 11,600-€ 11,800$ for the linear model and $€ 13,300-€ 14,300$ for the log-log model. The selected $O L S \log$-log model estimate of the turning point is then about $€ 13,000$, while the estimated dispersion across estimates is $€ 1,200$ ( $\hat{x}^{*}: € 13,279(1,207)$ ). Similarly for the Gini Index figures obtained from (1), the net and market Gini Index at the turning point being predicted at about $30 \%$ and $49 \%$, respectively, according to the selected $O L S \log$-log estimates $\left(\hat{y}_{G N}^{*}: 31 \% ; \hat{y}_{G W}^{*}: 32.2 \% ; \hat{y}_{G M}^{*}\right.$ : $48.5 \%)$.

In Figure 2 we plot the estimated EA-wide SS-FKC, obtained through cubic spline interpolation of the cross plots of predicted Gini Index against (across-country year-2000) trend real per capita income values. The estimated curve is then well behaved, showing the expected inverse-U shape, yet asymmetric, income inequality growing faster when per capita income increases toward the turning point than it is decreasing once the turning point income value is passed.

\subsection{EA member countries steady-state FKC properties}

By assuming the same structural parameters as holding for the EA-wide SS-FKC, the turning point for each EA member country SS-FKC can be computed from (4) as well. Comparison between own-country and area-wide SS-FKCs yields information on the degree of transitory divergence across EA member states. The latter is deemed to be transitory in the light of the existence of an EA-wide SS-FKC, and therefore of ongoing convergence toward its turning point, as determined by financial deepening.

In Figure 3, we plot the cross-plot of the estimated own-country SS-FKC turning points $\left(\hat{x}_{n}^{*}\right)$ against the corresponding financial development level $\left(\hat{f}_{n}^{*}\right)$, computed, for each country, as the average of the three financial deepening indicators, measured at mid-sample (year 2000) trend values. Corresponding figures for the EA-wide SS-FKC are also reported for comparison, where the EA-wide figure for financial development is the average of member country values $\left(\hat{x}^{*}: 13,279 ; \hat{f}^{*}: 82.2\right)$.

Projecting on the $x$ - and $y$-axix from the EA-wide SS-FKC values $\hat{x}^{*}$ and $\hat{f}^{*}$, the FKC turning point per capita income-financial development space is divided into four regions, i.e., high (low) per capita income and high (low) financial development, high (low) per capita income and low (high) financial development. As shown in Figure 3, the two former regions are empty, due to the inverse relationship holding between turning point and financial development levels.

EA countries can then be clustered into two groups. The first group $(D E V)$ shows high financial development and low SS-FKC turning point per capita income level; it is composed of the original EA members, i.e., Austria, Belgium, Finland, France, Germany, Greece, Ireland, Italy, Luxemburg, Portugal, Spain. ${ }^{11}$ The second group (UDV) shows low financial development and a high SS-FKC turning point per capita income level; it is composed of the most recent member states, i.e., Cyprus, Estonia, Latvia, Lithuania, Cyprus, Malta, Slovakia and Slovenia.

In the light of the above evidence, we then average across the two groups of countries, to obtain overall representative figures for the SS-FKC turning point per capita income levels $\left(\hat{x}_{D E V}^{*}\right.$

\footnotetext{
${ }^{11}$ The outlying behavior shown by the Netherlands is not surprising, due to the historically low values for the GDP shares of liquid liabilities and private credit, relatively to the other core euro area members. This is evident also from the estimation of the own-country steady-state FKC, the latter country turning out to be located on its upward sloped portion and showing a negative excess inequality during the crisis (see below).
} 
and $\left.\hat{x}_{U D V}^{*}\right)$. In the light of their outlying behavior, trimmed averages, discarding observations for the Netherlands and Lithuania, are also computed. ${ }^{12}$

As shown in Table 4, (OLS log-log model) reference estimates of the turning point for the two groups of countries are about $€ 10,000$ for $D E V$ and $€ 16,000$ for $U D V$, coherent with a financial development gap, between the two groups, of about 23 GDP points. Hence, a $22 \%$ contraction in the turning point value might be achievable for the new member countries, through further financial development, down to about $€ 13,000$, as estimated for the EA-wide SSFKC. Sizable would also be the contraction in income inequality for $U D V$ countries, particularly when assessed by means of the market income Gini Index $G M$, i.e., $-4 \%$, from $53 \%$ to $49 \%(-2.4 \%$ for the net income Gini Index $G N)$.

\subsection{Implied inequality values by the EA own-country steady-state FKCs}

Predicted Gini index values for the EA member countries can also be computed from (1). In Figure 4 we plot the (OLS log-log model) estimated EA own-country SS-FKCs, obtained through cubic spline interpolation of the cross-plots of the predicted Gini index values against (own-country) trend real per capita income. As is shown in the plots, the two groups of relatively more and less advanced countries can again be singled out. The former group, composed of Austria, Belgium, Finland, France, Germany, Greece, Ireland, Italy, Luxemburg, Portugal, Spain, as well as Cyprus and Slovenia, coherently shows a downward sloping FKC $(D S F K C)$, trend per capita income since the mid-1980s implicitly exceeding turning point levels. On the other hand, an upward sloping FKC can be noted for the latter group, composed of Estonia, Latvia, Lithuania, Malta and Slovakia $(U S F K C)$. Income inequality can then be expected to fall (increase) as economic growth will further progress for the group of more (less) developed EA countries, ceteris paribus.

\section{Financial crisis and inequality}

The analysis carried out in the previous Section is set within a long-term perspective, where financial deepening exerts a positive effect on economic growth. Within this perspective, financial development does not endanger economic stability through the generation of boom-bust financial cycles.

As shown by recent events, financial imbalances can however trigger sizable short-term fluctuations, real EA GDP having contracted $-5.9 \%$ during the subprime mortgage cum sovereign debt crisis $(-4.7 \%$ in $2009 ;-1.2 \%$ in $2012-2013)$. In Table 5 we report figures for the level and rate of growth of the Gini Index during the crisis. In particular, income inequality is computed as the average Gini Index level over the period 2008-2013 (GN,GW,GM), while its rate of change as the relative deviation of the latter average figure from its actual value in $2007\left(G N_{\%}\right.$, $\left.G W_{\%}, G M_{\%}\right)$. Similar figures are also computed and reported for trend real per capita income and financial development $\left(x, f ; x_{\%}, f_{\%}\right)$.

As shown in Table 5, on average across EA countries, during the period 2008-2013, GM (GN) increased $2.3 \%(1 \%)$; the corresponding figures for $x$ and $f$ are $-3.8 \%$ and $-9.7 \%$, respectively. The response of income and inequality to changes in financial depth is then inelastic: a $1 \%$ reduction in the financial development indicator being associated with a $-0.4 \%$ contraction in real per capita income and a $0.24 \%(0.1 \%)$ increase in the market (net) income Gini Index.

Scattered is however the evidence at the country level, also consistent with the strong national component in income distribution (see Gianetti, 2002; Bottazzi and Peri, 2003), market (net) income inequality having in general increased across countries, apart from Italy, Latvia and Lithuania, the Netherlands, Portugal (Belgium, Germany, Luxemburg). In order to gauge

\footnotetext{
${ }^{12}$ Lithuania has joined the EA only in December 2015, therefore not actually belonging to the EA during the period considered.
} 
further insights on the effects of the crisis, in Figure 5 we then report cross-plots for the average market and net income Gini Index, relative to average real per capita income and financial development.

As shown in Figure 5, a non linear linkage relates income inequality to both variables. In particular, both $G N$ and $G M$ monotonically fall as the level of real per capita income increases (column 1, top to bottom plots): hence, the financial crisis would have not undermined the validity of $\mathrm{KC}$, established over the whole estimation sample. Moreover, a U shaped linkage relates income inequality and financial development, as $G M$ and $G N$ both decrease as financial deepening raises up to a $90 \%-100 \%$ threshold value, to then increase thereafter (column 2); a kind of too-much finance phenomenon can then be noted, where the highest average Gini Index figures are actually shown by the countries which were affected the most by the sovereign debt crisis, i.e., Cyprus, Ireland, Portugal and Spain, as well as Greece and Italy, also showing a financial deepening indicator value well in excess of the threshold..$^{13}$

Comparison between net and market income inequality figures is then strongly informative on the effectiveness of redistributive policies and automatic stabilizers, particularly for the countries which were most severely hit by the sovereign debt crisis. Among the latter, Spain can be singled out as the EA member country where inequality has increased the most during the crisis, also when the effects of redistributive policies are accounted for $\left(11.3 \%\right.$ and $7.3 \%$, for $G M_{\%}$ and $G N_{\%}$, respectively); similarly Greece (6\% and $4.3 \%$, for $G M_{\%}$ and $G N_{\%}$, respectively) and Cyprus ( $2 \%$ and $1.9 \%$, for $G M_{\%}$ and $\left.G N_{\%}\right)$; on the other hand, Italy, Portugal and Ireland are the countries where inequality has been affected the least or even decreased, due to redistributive policies (IT: $-0.1 \%$ and $-1.1 \%$; PT: $-0.9 \%$ and $-3.6 \%$; IE: $8.5 \%$ and $-1.7 \%$, for $G M_{\%}$ and $G N_{\%}$, respectively).

\subsection{The Gini index anomaly}

In Table 5 we also report figures for the Gini Index anomaly during the crisis period, computed as the average deviation of the actual Gini Index from its predicted value, according to the corresponding SS-FKC $\left(G N_{a}, G W_{a}, G M_{a}\right)$. Hence, the Gini Index anomaly measures excess inequality generated by factors unrelated to trend economic and financial development, allowing for a counterfactual comparison of the effects of the crisis, relative to a non-crisis scenario. As shown in the Table, the anomaly is on average sizable, about $3.5 \%$ for $G M_{a}$, also when redistributive policies are taken into account $\left(1.5 \%\right.$ for $\left.G N_{a}\right)$.

In Figure 5 we also relate the anomalies to the level of both economic and financial development (columns 3 and 4, respectively). An inverse-U shaped linkage can then be noted for excess inequality and real per capita income, reminiscent of the $\mathrm{KC}$ itself, as the anomaly raises until a per capita income threshold of about $€ 25,000$ is achieved, to fall thereafter. On the other hand, excess inequality monotonically increases with the level of financial development.

The two groups of relatively more and less advanced countries can then be singled out again, the former showing a positive anomaly falling with the level of economic development, yet increasing with financial deepening ( 6.3 for $G M_{a} ; 3.1$ for $G N_{a}$ ); the latter showing a negative anomaly $\left(-3.2 \%\right.$ for $G M_{a} ;-2.1 \%$ for $\left.G N_{a}\right)$.

The crisis, through its recessionary impact, would have then exercised adverse effects for both groups of countries. In fact, a contraction in real per capita income, occurring along the upward (downward) sloped portion of the FKC, would cause a reduction (increase) in income inequality, therefore generating lower (higher) income inequality than predicted under a noncrisis scenario. Consistent with the too much finance phenomenon already detected, the positive anomaly is actually largest for the countries most severely hit by the sovereign debt crisis, i.e., Cyprus, Ireland, Portugal and Spain (on average $8.2 \%$ for $G M_{a}$ and $3.6 \%$ for $G N_{a}$ ), yet not

\footnotetext{
${ }^{13}$ It is worth noticing that the estimated threshold values for financial development are very close to those obtained by Arcand et al. (2015) and Borio and Lowe (2004), using different data and econometric techniques.
} 
Greece and Italy ( $4.8 \%$ for $G M_{a}$ and $0.9 \%$ for $G N_{a}$ ), and showing a financial deepening index value well in excess of the $90 \%-100 \%$ threshold. Income distribution would have then worsened not only for peripheral EA member countries, which were most severely hit by the financial crisis, but also for those showing much sounder public finances, i.e., Austria, Belgium, Finland, France, Germany and Luxemburg. For the latter countries, the anomaly is positive and large not only when assessed using $G M_{a}(5.1 \%$ on average), but also once redistributive policies are taken into account $\left(3.1 \%\right.$ on average for $\left.G N_{a}\right)$.

\section{Conclusions}

The paper yields innovative contributions to the financialization-income inequality literature by introducing a new specification of the Kuznets curve, where turning point per capita income is conditioned to the level of financial development. It then provides new evidence on real income convergence for the euro area since the mid-1980s, with a special focus on the subprime and sovereign debt financial crises.

We find strong evidence in favor of an EA-wide steady-state financial Kuznets curve, i.e., of a long-term inverse-U shaped linkage between inequality and income development, where financial deepening contributes to a more even distribution of income by lowering the per capita income level at which the turning point of the $\mathrm{KC}$ occurs. We hold the latter finding as evidence of ongoing convergence, across EA members, toward a common turning point per capita income level (about $€ 13,000$ ), with net and market income Gini Index values at the turning point close to $30 \%$ and $49 \%$, respectively.

Comparison of EA-wide and own member country FKCs, allows two single out two groups of countries, composed of the more and the less advanced EA member states, showing turning point per capita income levels of about $€ 10,000$ and $€ 16,000$, respectively, consistent with a financial development gap, between the two groups, of about 23 GDP points. A $-22 \%$ contraction in turning point per capita income would then appear to be attainable by the most recent member countries, i.e., Cyprus, Estonia, Latvia, Lithuania, Malta, Slovakia and Slovenia, through further financial deepening. Sizable would also be the associated contraction in income inequality, particularly when assessed by means of the market income Gini Index, i.e., $-4 \%$, from $53 \%$ to $49 \%$ (-2.4\% for the net income Gini Index).

While the financial crisis would have not undermined the validity of the EA steady-state FKC, as an inverse linkage between inequality and economic development still holds also during the 2008-2013 period, it has however sizably increased income inequality for all EA member countries. In fact, while not noticeable when assessed using actual Gini Index figures, a counterfactual analysis, comparing actual and predicted Gini Index figures, point to higher inequality than it would have otherwise occurred in a non-crisis scenario also for those countries which were little affected by the sovereign debt crisis. A too much finance phenomenon is actually detected during the crisis, since inequality falls as financial deepening increases up to a threshold value of 90-100 GDP points, to then raise thereafter; coherently, the countries that were affected the most by the sovereign debt crisis show the highest figures for both variables.

From a policy perspective, ensuring financial stability, i.e., financial market conditions where asset price fluctuations about fundamentals are dampened, is instrumental not only to foster stable economic growth, but also to achieve a more even distribution of income. In this respect, the stable macroeconomic environment prevailing since the mid-1980s in core EA, as well as in other OECD countries (the so called Great Moderation), was temporarily destabilized by the US subprime financial crisis and ensuing Great Recession in the late 2000s, as a sequence of asset price misalignments, involving initially bonds, stocks and house prices, and then oil and non-energy commodity prices, originated from persistently too low real interest rates (Bagliano and Morana, 2015).

The latter is also the same environment where the Great Inequality phenomenon, i.e., the 
persistent rise in income inequality, ongoing since the mid-1980s in OECD countries, originated. In addition to traditional explanations, related to the effects of globalization, skill-biased technical change, unionization, problems with access to education and the decline in the progressivity of the tax schedule at the upper tail of the income distribution (OECD, 2011), the contribution of financial instability to the phenomenon is non negligible, at least during the 2008-2013 period.

While we point to Delli Gatti et al. (2015) and DeGrauwe (2015) for policy measures to dispel the recessionary bias currently affecting the EA, we also highlight the need of further correcting those factors that made unstable a macroeconomic environment otherwise stable, i.e., excessive risk taking of financial intermediaries, boosted by financial deregulation and innovation and misled risk perceptions, in particular.

In this respect, financial stability should be counted as an additional, financial pillar to the economic, social and environmental pillars of the Lisbon Strategy, continued in the Europe 2020 Strategy, in the perspective of truly making Europe "the most competitive and dynamic knowledge-based economy in the world, capable of sustainable economic growth and stable financial development, with more and better jobs and greater social cohesion". The creation of a European Banking Union together with a unified banking supervision mechanism, as well as the most recent proposal for a Capital Markets Union, surely are important steps in this direction (European Commission, 2014, 2015). 


\section{References}

[1] Aghion, P, Howitt, P., 1997. A Schumpeterian Perspective on Growth and Competition. In: Kreps DM, Wallis KF Advances in Economics and Econometrics: Theory and Applications, vol. 2. Cambridge University Press, 279-317.

[2] Arcand, J.-L., Berkes, E., Panizza, U., 2015. Too much finance? Journal of Economic Growth 20, 105-148.

[3] Bagliano, F.C., Morana, C., 2011. The Effects of the US Economic and Financial Crises on Euro Area Convergence in W. Meeusen (ed.), The Economic Crisis and Euro Area Integration, Edward Elgar, UK, 2011, ch.7, ISBN: 1849804206.

[4] Bagliano, F.C., Morana, C., 2015. It ain't over till it's over: A global perspective on the Great ModerationGreat Recession interconnection. DEMS Working Paper Series no.303.

[5] Bangake, C., Eggoh, J.C., 2011. Further evidence on finance-growth causality: A panel data analysis. Economic System 35, 176-188.

[6] Barrios, S., Strobl, E., 2009. The dynamics of regional inequalities. Regional Science and Urban Economics $39,575-591$.

[7] Barro, R., 2000. Inequality and Growth in a Panel of Countries. Journal of Economic Growth, 5: 5-32.

[8] Beck, T., Levine, R., Loayza, N., 2000. Finance and the sources of growth. Journal of Financial Economics $58,261-300$.

[9] Beck, T., Demirguc-Kunt, A., Levine, R., 2007. Finance, inequality and the poor. Journal of Economic Growth 12, 27-49.

[10] Beltratti, A., Morana, C., 2007. Does the stock market affect income distribution? Some empirical evidence for the US. Applied Economics Letters 14, 99-104.

[11] Bergh, A., Nilsson, T., 2010. Do liberalization and globalization increase income inequality? European Journal of Political Economy 26, 488-505.

[12] Bertola, G., 2013. Policy coordination, convergence, and the rise and crisis of EMU imbalances. European Commission, Directorate General for Economic and Financial Affairs, Economic Papers no. 490.

[13] BIS, 2012. Innovations in retail payments. Report of the Working Group on Innovations in Retail Payments, Bank for International Settlements, Basel, Switzerland, ISBN 92-9131-127-8.

[14] Borio, C., Lowe, P., 2004. Securing sustainable price stability: should credit come back from the wilderness? BIS Working Papers No 157.

[15] Bottazzi, L., Peri, G., 2003. Innovation and spillovers in regions: evidence from European patent data. European Economic Review 47, 687-710.

[16] Bradford, D.F., Fender, R., Shore S.H., Wagner, M., 2005. The Environmental Kuznets Curve: Exploring a Fresh Speci cation. Contributions to Economic Analysis and Policy 4, No. 1, Article 5.

[17] Chandavarkar, A., 1992. Of finance and development: neglected and unsettled questions. World Development $22: 133-142$

[18] Cihak, M., Demirguc-Kunt, A., Feyen, E., Levine, R., 2013. Financial development in 205 economies, 1960 to 2010. Journal of Financial Perspectives 1, 17-36.

[19] Clarke, G., Xu, G., Lixin, C., Heng-Fu, Z., 2006. Finance and income inequality; What do the data tell us? Southern Economic Journal 72, 578-596.

[20] Davis, J., Henderson, J.V., 2003. Evidence on the Political Economy of the Urbanization Process. Journal of Urban Economics, 53, 98-125. 
[21] DeGrauwe, P., 2015. The legacy of the eurozone crisis and how to overcome it. London School of Economics, mimeo.

[22] Delli Gatti, D., Lossani, M., Morana, C., Saraceno, F., Tirelli, P., 2015. Eurozone in the doldrums. New policies and institutions to escape the fate of recurring crises. Università di Milano-Bicocca, mimeo.

[23] Deidda, L., 2006. Interaction between economic and financial development. Journal of Monetary Economics $53,233-248$.

[24] Demirgüç-Kunt, A., Levine, R., 2008, Finance, Financial Sector Policies, and Long-Run Growth. World Bank Policy Research Working Paper No. 4469

[25] D'Errico, M., Macchiarelli, C., Serafini, R., 2015. Differently unequal. Zooming-in on the distributional dimensions of the crisis in euro area countries. Economic modeling, forthcoming.

[26] Dreher, A., Gaston, N., 2008. Has globalization increased inequality? Review of International Economics $16,516-536$.

[27] European Commission, 2014. A comprehensive EU response to the financial crisis: substantial progress towards a strong financial framework for Europe and a banking union for the eurozone. MEMO, Update 2, Brussels, 28 March 2014.

[28] European Commission, 2015. Action Plan on Building a Capital Markets Union. COM(2015) 468 final, Brussels, 30 September 2015.

[29] Gianetti, M., 2002. The effects of integration on regional disparities: convergence, divergence or both? European Economic Review 46, 539-567.

[30] Gimet, C., Lagoarde-Segot, T., 2011. A close look at financial development and income distribution. Journal of Banking and Finance 35, 1698-1713.

[31] Greenwood, J., Jovanovich, B., 1990. Financial development, growth and the distribution of income. Journal of Political Economy 98, 1076-1107.

[32] Gros, D., 2013, Foreign debt versus domestic debt in the euro area. Oxford Review of Economic Policy, 29, $502-517$.

[33] Hall, R.E., 2001. The stock market and capital accumulation, American Economic Review 91, 1185-1202.

[34] Jauch, S., Watzka, S., (2012). Financial Development and Income Inequality: A Panel Data Approach. CESIFO Working Paper No. 3687, Category 6.

[35] Jaumette, F., Lall, S., Papageorgiou, C., 2008. Rising income inequality: Technology or trade and financial globalization? IMF Working Paper \\#185/08.

[36] Kappel, V., 2010. The effects of financial development on income inequality and poverty, CER-ETH, WP \#10/127.

[37] Kim, D-H., Lin, S-L., 2011. Nonlinearity in the nancial development-income inequality nexus. Journal of Comparative Economics 39, 310-325.

[38] Kuznets, S., 1955. Economic growth and income inequality. American Economic Review 45, 1-28.

[39] Laeven, L., Levine, R., Michalopoulos, S., 2015. Financial innovation and endogenous growth, Journal of Financial Intermediation 24, 1-24.

[40] La Porta, R., Lopez-de-Silanes, F., Shleifer, A., Vishny, R.W., 1997. Legal determinants of external finance. Journal of Finance 52, 1131-1150.

[41] Lee, J.E., 2006. Inequality and globalization in Europe. Journal of Policy Modeling 28, 791-796.

[42] Levine, R., Loayza, N., Beck, T., 2000. Financial intermediation and growth: Causality and causes. Journal of Monetary Economics 46, 31-77.

[43] Lewbel, A., 2012. Using heteroskedasticity to identify and estimate mismeasured and endogenous regressor models. Journal of Business and Economic Statistics 30, 67-80. 
[44] Li, H., Squire, L., Zou, H., 1998. Explaining international and intertemporal variations in income inequality. Economic Journal 108, 26-43.

[45] Lucas, R.E., 1988. On the mechanisms of economic development. Journal of Monetary Economics 22, 3-42.

[46] Morana, C., 2015, Model Averaging by Stacking, Open Journal of Statistics, forthcoming.

[47] OECD, 2011. Divided we stand: Why inequality keeps rising, OECD Publishing, Paris.

[48] OECD, 2013. Crisis squeezes income and puts pressure on inequality and poverty. Results from OECD Income Distribution Database, OECD Publishing, Paris.

[49] OECD, 2014. Does income inequality hurt economic growth? OECD Publishing, Paris.

[50] Patrick, H.T., 1966. Financial development and economic growth in underdeveloped countries. Economic Development and Cultural Change 14, 174-189.

[51] Rodriguez-Pose, A., Tselios, V., 2009. Education and income inequality in the regions of the European Union. Journal of Regional Science 49, 411-437.

[52] Roine, J., Vlachos, J., Waldenström, D., 2009. The long-run determinants of inequality: What can we learn from top income data?. Journal of Public Economics 93, 974-998.

[53] Smith, B.D., 2003. Taking intermediation seriously. Journal of Money, Credit and Banking 35, 1319-1357.

[54] UNU-WIDER, 2014. World Income Inequality Database (WIID3.0A), June 2014. http : $==$ www:wider:unu:edu $=$ research $=$ WIID $3 \mathrm{a}=\mathrm{enGB}=$ database $=$

[55] Solt, F., 2014. The Standardized World Income Inequality Database. Working paper. SWIID Version 5.0, October 2014.

[56] Townsend, R.M., Ueda, K., 2006. Financial deepening, inequality, and growth: a model-based quantitative evaluation. Review of Economic Studies 73, 251-293.

[57] Wan, G., 2004. Accounting for income inequality in rural China: a regression-based approach. Journal of Comparative Economics 32, 348-363. 


\section{Appendix A: The data}

The dataset is an unbalanced panel of annual observations for the 19 current euro area member countries, covering the period 1985 through $2013(N=19$ and $T=28)$, i.e., Austria, Belgium, Cyprus, Estonia, Finland, France, Germany, Greece, Ireland, Italy, Latvia, Lithuania, Luxemburg, Malta, the Netherlands, Portugal, Slovakia, Slovenia and Spain. ${ }^{14}$

In particular, income inequality $(y)$ is measured by means of the market $(G M)$ and net income $(G N)$ Gini Index, computed by using household market and disposable income (post-tax, post-transfer), respectively, as reported in the Standardized World Income Inequality Database (SWIID), recently updated by Solt (2014). In the light of its wide use in the empirical literature, the net income Gini Index $(G W)$, reported in the World Income Inequality Database (WIID; UNU-WIDER, 2014), is also employed in the analysis. Their sample averages are employed for estimation.

The level of economic development is measured by real per capita GDP $(x)$, obtained by the World Bank Development Indicators Database (2014 Edition), at year 2005 constant prices. Moreover, three distinct proxies for financial development $(f)$ are employed, i.e., $i)$ the GDP share of credit to the private sector $(c), i i)$ the GDP share of liquid liabilities $(m)$, iii) the GDP share of stock market capitalization $(s)$. Data sources are the International Financial Statistics (IFS) database for $c$ and $s$; the European Central Bank (ECB) for $m$. These variables have been widely employed as alternative measures of financial depth in previous studies (see Li et al., 1998; Clarke et al., 2006; Beck et al., 2007; Jaumotte et al., 2008; Rodriguez-Pose and Tselios, 2009; Roine et al., 2009; Kappel, 2010; Kim and Lin, 2011; Gimet and Lagoarde-Segot, 2011 and Jauch and Watzka, 2012), despite their information content is not univocal.

In particular, credit to the private sector is measured by the IFS Claims on Private Sector series, which include gross credit from the financial system to individuals, enterprises, nonfinancial public entities (not included under net domestic credit), and other financial institutions (not included elsewhere). While higher values of its GDP share signal easier access to finance by the private sector, its widening beyond given reference values (80\%-100\%) is also consistent with growing financial fragility and instability (Borio and Lowe, 2004 and Arcand et al., 2015). By smoothing out short-lived fluctuations, its underlying trend should provide a reliable measure of financial development, being strongly correlated with alternative measures of access to finance, likewise the number of ATMs or the number of bank branches per population or per square mile (Jauch and Watzka, 2012), as well as the GDP share of total banking assets (Cihak et al., 2013).

The GDP share of liquid liabilities is computed using M3, which, by including total deposits held by the private sector in the banking system, yields a measure of the liability side of the financial system. Higher values of this indicator imply easier access to finance. Moreover, it reflects trust of creditors in the financial system. Being the inverse of the income velocity of circulation of money, it also conveys information concerning the pace of innovations in the payment system, as for instance those brought about by the introduction of ATMs since the early 1980s, as well as, more recently, the use of card, internet and mobile payments, electronic bill presentment and improvements in infrastructure and security (BIS, 2012). Yet, a caveat applies as, by also reflecting the monetary overhang in the economy, higher values of this series might signal incoming macroeconomic/price instability, through the demand-pull channel of inflation. Hence, also the GDP share of liquid liabilities requires short-lived fluctuations to be smoothed out in order to yield an accurate measure of financial development.

In addition, the GDP share of stock market capitalization is an indicator of stock market development, measuring the easiness for listed firms of accessing the market for raising capital. Moreover, according to Hall (2001), the capital stock measured by the market value of equities

\footnotetext{
${ }^{14}$ For Slovakia, Slovenia, Estonia and Lithuania a smaller data set is available, observations starting in 1992, 1995, 1995 and 1991, respectively.
} 
is a comprehensive indicator, reflecting both tangible and intangible assets firms employ in production, consistent with the notion of aggregate capital stock (physical plus human) postulated in endogenous growth theory. The GDP share of stock market capitalization then also yields a measure of the capital to GDP ratio, potentially conveying broader information on the linkage between financial development and income distribution, through its role in fostering capital accumulation. As for the other two above measures of financial development, also the latter indicator might yield not univocal signals, especially when wide and swift oscillations, unrelated to fundamentals, occur during boom-bust stock market cycles. The latter issue is surely of interest for the current study, given that over the sample investigated two major disruptive financial events have manifested, i.e., the burst of the dot-com bubble in the early 2000s and the subprime mortgage cum sovereign debt crisis in the late 2000s and early 2010s. As for credit and M3, by conditioning on its underlying trend, we then expect to be able to control for the noise contributed by boom-bust cycles.

The variables $x$ and $f$, used in the cross-sectional analysis, are then computed as midsample (year 2000) estimated trend values ${ }^{15}$, while $g$ is the trend growth rate sample average for $x$. These transformations of the original series allow to cast the analysis within a long-term perspective as in Bradford et al. (2005). Having filtered out short-lived fluctuations, potentially related to various forms of instability, the data employed in the analysis are then coherent with a framework where financial development is associated with prevailing economic and financial stability.

Finally, in order to account for the influence of factors other than economic growth and financial development on income inequality, different control variables are included, i.e., $i)$ the age dependency ratio $(D E P)^{16} ;$ ii $)$ the GDP share of government spending $(P E)$, iii) the spread between the interest rate on 10-year government bonds relatively to interest rate paid on 10-year German Treasury bonds $(S P R) ; i v)$ trade openness (TRD), as measured by the GDP share of exports plus imports; $v$ ) the population share living in urban areas $(U R B)$. All of the above indicators are taken from the World Bank Development Indicators Database (2014), with the only exception of $S P R$, whose source is the IFS database. Their sample averages are employed for estimation.

Concerning their expected effects, the impact of a higher dependency ratio $D E P$ on inequality is ambiguous. In fact, on the one hand a higher $D E P$ might be expected to be positively correlated with government policies directed to the young and/or the elderly, i.e., to interventions such as family and retirement benefits, which should lessen income inequality (Dreher and Gaston, 2008; Bergh and Nilsson, 2010); on the other hand, a higher DEP might also be associated with a larger share of population without a regular wage, and therefore positively correlated with income inequality (Wan, 2004).

Moreover, as government spending $P E$ is related to the size of the welfare system, as well as with the provision of public goods, the degree of intervention in the marketplace and the possible use of redistributive expenditures, $P E$ is expected to be negatively correlated with income inequality. Similarly for the Treasury bills spread $S P R$, which can be expected to be positively correlated with government spending in the long-term.

In addition, international trade theories based on the Heckscher-Ohlin framework imply that trade openness $T R D$ in general exerts downward pressure on the wage of unskilled workers especially in high-income countries. Therefore, $T R D$ is expected to be positively correlated with income inequality (Bergh and Nilsson, 2010).

Lastly, an increase in the population share living in urban areas $U R B$ is expected lo lead to lower income inequality through a growth enhancing effect of urbanization, yielding higher

\footnotetext{
${ }^{15}$ See below for details on trend extraction.

${ }^{16}$ This variable is computed as the ratio of dependent people younger than 15 or older than 64 to the working-age population (15-64 years old).
} 
productivity in the urban sector (Davis and Henderson, 2003; Bergh and Nilsson, 2010). ${ }^{17}$

\subsection{Data filtering}

In order to disentangle short- and long-term components, real per capita GDP and the GDP shares of credit to the private sector, liquid liabilities and stock market capitalization are deterministically filtered. This is also in the light of the short-sample available, which lead us to discard stochastic methods. In particular, the trend component for the generic series $w_{t}$ is estimated by $O L S$, averaging across the four deterministic specifications nested in the model

$$
w_{t}=\beta_{0}+\beta_{1} t^{0.5}+\beta_{2} t+\beta_{3} t^{2}+\beta_{4} t^{3}+\varepsilon_{t} \quad t=1, \ldots, T
$$

i.e., in addition to the above general specification, the models

$$
\begin{aligned}
& w_{t}=\beta_{0}+\beta_{1} t+\beta_{2} t^{0.5}+\beta_{3} t^{2}+\varepsilon_{t} \\
& w_{t}=\beta_{0}+\beta_{1} t+\beta_{2} t^{0.5}+\varepsilon_{t} \\
& w_{t}=\beta_{0}+\beta_{1} t+\varepsilon_{t}
\end{aligned}
$$

are estimated, where $\varepsilon_{t}$ is a stationary disturbance.

Then, a trend cycle decomposition is computed from each of the above four models, yielding

$$
w_{t}=\hat{w}_{j, t}+\hat{\varepsilon}_{j, t} \quad j=1,2, \ldots, 4
$$

and the final estimates, robust to trend model uncertainty, $w_{\text {trend }_{t}}=\frac{1}{4} \sum_{j=1}^{4} \hat{w}_{j, t}, w_{c y c l e t}=$ $\frac{1}{4} \sum_{j=1}^{4} \hat{\varepsilon}_{j, t}$

As the estimated cycle $\left(\hat{\varepsilon}_{j}\right)$ is zero-mean by construction, the average trend value in the sample coincides with the sample mean of the actual series.

\section{Appendix B: Empirical properties of the financial Kuznets curve}

Details for the computation of the empirical properties of the EA-wide and EA own member country steady-state financial Kuznets curves are reported below.

\subsection{The EA-wide steady-state FKC turning point per capita income}

On the basis of the estimated structural parameters $\lambda_{0}$ and $\lambda_{1}$, the turning point of the EA-wide steady-state FKC is then computed using (4) as

$$
\hat{x}^{\star}=\hat{\lambda}_{0}+\hat{\lambda}_{1} \hat{f}^{*}
$$

where $\hat{f}^{*}$ is the across-country average of the financial development variable, as yield by the average of the GDP shares of credit to the private sector $(c)$, liquid liabilities $(m)$ and stock market capitalization $(s)$, each measured by its trend value at mid-sample (year 2000). Three estimates of the turning point income level are then available, for each specification, according

\footnotetext{
${ }^{17}$ Consistent with the available literature on income distribution inequality, other control variables were also considered in the analysis: i.e., the gross tertiary school enrollment ratio, which captures human capital effects; the CPI inflation rate, which yields information on the degree of macroeconomic/price instability; the unemployment rate, which yields information on cyclical goods and labor market conditions. They were never found statistically significant in our regressions.
} 
to the estimator employed in (6) and (7), i.e., $O L S\left(\hat{\lambda}_{i_{O L S}} ; i=0,1\right), G M M\left(\hat{\lambda}_{i_{G M M}} ; i=0,1\right)$, as well as their average $(M I X)\left(\hat{\lambda}_{i_{M I X}}=\frac{\hat{\lambda}_{i_{O L S}}+\hat{\lambda}_{i_{G M M}}}{2} ; i=0,1\right)$.

Since standardized variables were employed in the estimation of (6) and (7), $\hat{x}^{\star}$ for the linear model is

$$
\begin{aligned}
\hat{x}^{\star} & =\bar{x}_{x}+\left(\hat{\lambda}_{0}+\hat{\lambda}_{1} \hat{f}^{*}\right) \hat{\sigma}_{x} \\
& =\bar{x}_{x}+\hat{\lambda}_{0} \hat{\sigma}_{x}
\end{aligned}
$$

while for the log-log model one has

$$
\begin{aligned}
\hat{x}^{\star} & =\exp \left(\bar{x}_{\ln x}+\left(\hat{\lambda}_{0}+\hat{\lambda}_{1} \ln \hat{f}^{*}\right) \hat{\sigma}_{\ln x}\right) \\
& =\exp \left(\bar{x}_{\ln x}+\hat{\lambda}_{0} \hat{\sigma}_{\ln x}\right)
\end{aligned}
$$

where $\bar{x}_{x}\left(\bar{x}_{\ln x}\right)$ is the average of mid-sample (year 2000) trend (log trend) real per capita income values across-country, and $\hat{\sigma}_{x}\left(\hat{\sigma}_{\ln x}\right)$ its sample standard deviation.

\subsection{Implied inequality values by the EA-wide steady-state FKC}

Predicted EA-wide Gini Index values can be obtained from (1) as

$$
\begin{gathered}
\tilde{y}_{G I N I, n}=\hat{b}_{L M} x_{n}+\hat{c}_{L M} x_{n}^{2} \\
\tilde{y}_{G I N I, n}=\exp \left(\hat{b}_{L L} \ln x_{n}+\hat{c}_{L L} \ln x_{n}^{2}\right)
\end{gathered}
$$

for the linear $(L M)$ and log-log $(L L)$ models, respectively, where GINI $=G N, G M, G W ; x_{n}$ is trend real per capita income at mid-sample value (year 2000) for the generic $n$th country, $n=1,2, \ldots 19$. Moreover, according to the theoretical framework, $\hat{c}_{L M}=-\hat{\beta}_{0}^{L M} / 2, \hat{b}_{L M}=$ $-\hat{\beta}_{0}^{L M} \times \hat{x}^{*}, \hat{c}_{L L}=-\hat{\beta}_{0}^{L L} / 2, \hat{b}_{L L}=-\hat{\beta}_{0_{j}}^{L L} \times \hat{x}^{*}$, where $\hat{\beta}_{0}^{L M}$ and $\hat{\beta}_{0}^{L L}$ is the destandardized $\hat{\beta}_{0}$ obtained from the linear and log-log model, respectively, and the selected $O L S \log$-log model estimate of the FKC turning point real per capita income level $\left(\hat{x}^{*}\right)$ is employed in all cases. According to the estimator employed, i.e., $O L S, G M M, M I X$, three different set of values are then available for each inequality indicator.

As the unknown scaling factor $a$ in (1) is neglected in (16) and (17), the scaled estimate of the Gini index is then obtained by applying the standardization

$$
\hat{y}_{G I N I, n}=\hat{\mu}_{G I N I}+\hat{\sigma}_{G I N I}\left(\frac{\tilde{y}_{G I N I, n}-\bar{y}_{G I N I}}{\sigma_{\tilde{y}_{G I N I}}}\right)
$$

where $\hat{\mu}_{G I N I}$ is the average across countries and time of the Gini index variable, GINI= $G N, G M, G W$ and $\hat{\sigma}_{G I N I}$ its sample standard deviation; $\bar{y}_{G I N I}$ is the sample mean of the predicted figures $\tilde{y}_{G I N I, n}$ from (16) or (17) and $\sigma_{\tilde{y}_{G I N I}}$ the corresponding sample standard deviation.

\subsection{The EA member countries steady-state FKC}

By assuming the same structural parameters as holding for the EA-wide steady-state financial Kuznets curve, the turning point for each EA member country steady-state FKC can be computed from (4) as well, yielding, for the generic $n$th country, $n=1, \ldots, 19$

$$
\hat{x}_{n}^{*}=\bar{x}_{x}+\left(\hat{\lambda}_{0}+\hat{\lambda}_{1} \hat{f}_{n}^{*}\right) \hat{\sigma}_{x}
$$




$$
\hat{x}_{n}^{*}=\exp \left(\bar{x}_{\ln x}+\left(\hat{\lambda}_{0}+\hat{\lambda}_{1} \ln \hat{f}_{n}^{*}\right) \hat{\sigma}_{\ln x}\right)
$$

for the linear and log-log model, respectively. In the above formula $\hat{f}_{n}^{*}$ is the average of the three (standardized) financial deepening variables available $\left(c_{n}, m_{n}, s_{n}\right)$ for each country $n$, measured at mid-sample (year 2000) trend value and $\ln \hat{f}_{n}^{*}$ the average of their (standardized) $\operatorname{logs} ; \bar{x}_{x}\left(\bar{x}_{\ln x}\right)$ is the across-country average of trend (log trend) real per capita income at mid-sample (year 2000) value and $\hat{\sigma}_{x}\left(\hat{\sigma}_{\ln x}\right)$ its sample standard deviation. Hence, six distinct turning point per capita income estimates are available for each country, according to functional form specification (linear and log-log) and estimator ( $L S, G M M, M I X)$.

\subsection{Implied inequality values by the EA own-country steady-state FKCs}

As for the EA-wide case, predicted EA member country Gini index values can be computed from $(1$ as

$$
\tilde{y}_{G I N I, n, t}=\hat{b}_{L M} x_{n, t}+\hat{c}_{L M} x_{n, t}^{2} \quad t=1, \ldots, T
$$

for the linear model, and

$$
\tilde{y}_{G I N I, n, t}=\exp \left(\hat{b}_{L L} \ln x_{n, t}+\hat{c}_{L L} \ln x_{n, t}^{2}\right)
$$

for the log-log model, where $x_{n, t}$ is real trend per capita income for country $n$ at time period $t$, and all the other terms are defined as above.

Moreover, scaled Gini Index estimates can be coputed as

$$
\hat{y}_{G I N I, n, t}^{*}=\hat{\mu}_{G I N I_{n}}+\hat{\sigma}_{G I N I_{n}}\left(\frac{\tilde{y}_{G I N I, n, t}-\bar{y}_{G I N I, n}}{\sigma_{\tilde{y}_{G I N I, n}}}\right) \quad t=1, \ldots, T
$$

where $\hat{\mu}_{G I N I_{n}}$ is the sample mean, computed over the available time period, of the Gini index variable, $G I N I=G N, G M, G W$, for country $n$, and $\hat{\sigma}_{G I N I, n}$ its sample standard deviation;

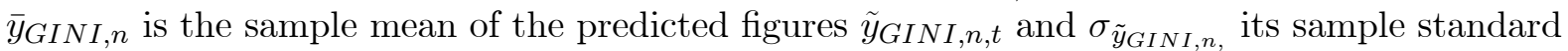
deviation. Six different sets of predicted values for each Gini index are then obtained for each country, according to functional form specification (linear and log-log) and estimator $(L S$, $G M M, M I X)$. 


\begin{tabular}{|c|c|c|c|c|c|c|c|}
\hline & $\begin{array}{l}(1) \\
\text { OLS }\end{array}$ & $\begin{array}{l}(2) \\
\text { OLS }\end{array}$ & $\begin{array}{l}(3) \\
\text { OLS }\end{array}$ & $\begin{array}{l}(4) \\
\text { OLS }\end{array}$ & $\begin{array}{c}(5) \\
\text { GMM }\end{array}$ & $\begin{array}{c}\text { (6) } \\
\text { GMM } \\
\end{array}$ & $\begin{array}{c}(7) \\
\text { GMM }\end{array}$ \\
\hline$x g$ & $\begin{array}{c}-0.122^{* *} \\
(0.054)\end{array}$ & $\begin{array}{c}-0.193^{* * *} \\
(0.065)\end{array}$ & $\begin{array}{c}-0.327 * * * \\
(0.105)\end{array}$ & $\begin{array}{c}-0.329 * * * \\
(0.092)\end{array}$ & $\begin{array}{l}-0.297^{*} \\
(0.163)\end{array}$ & $\begin{array}{c}-0.315^{* *} \\
(0.142)\end{array}$ & $\begin{array}{c}-0.332 * * * \\
(0.115)\end{array}$ \\
\hline $\boldsymbol{g}$ & $\begin{array}{l}-0.001 \\
(0.056)\end{array}$ & $\begin{array}{c}-0.022 \\
(0.060)\end{array}$ & $\begin{array}{l}-0.114 \\
(0.086)\end{array}$ & $\begin{array}{c}-0.220^{* * *} \\
(0.084)\end{array}$ & $\begin{array}{c}-0.203^{* *} \\
(0.103)\end{array}$ & $\begin{array}{c}-0.212^{* *} \\
(0.099)\end{array}$ & $\begin{array}{c}-0.221^{* *} \\
(0.088)\end{array}$ \\
\hline$f g$ & $\begin{array}{c}-0.395 * * * \\
(0.080)\end{array}$ & $\begin{array}{c}-0.327^{* * *} \\
(0.098)\end{array}$ & $\begin{array}{c}-0.298^{* * *} \\
(0.102)\end{array}$ & $\begin{array}{c}-0.337 * * * \\
(0.097)\end{array}$ & $\begin{array}{l}-0.386^{*} \\
(0.224)\end{array}$ & $\begin{array}{l}-0.358^{*} \\
(0.185)\end{array}$ & $\begin{array}{c}-0.332^{* *} \\
(0.146)\end{array}$ \\
\hline$D E P$ & $\begin{array}{c}0.648 * * * \\
(0.054)\end{array}$ & $\begin{array}{c}0.546^{* * *} \\
(0.050)\end{array}$ & $\begin{array}{c}0.573^{* * *} \\
(0.056)\end{array}$ & $\begin{array}{c}0.576 * * * \\
(0.056)\end{array}$ & $\begin{array}{c}0.584 * * * \\
(0.066)\end{array}$ & $\begin{array}{c}0.579 * * * \\
(0.058)\end{array}$ & $\begin{array}{c}0.575^{* * *} \\
(0.059)\end{array}$ \\
\hline$P E$ & $\begin{array}{c}-0.526^{* * *} \\
(0.074)\end{array}$ & $\begin{array}{c}-0.540^{* * *} \\
(0.071)\end{array}$ & $\begin{array}{c}-0.571^{* * *} \\
(0.068)\end{array}$ & $\begin{array}{c}-0.533^{* * *} \\
(0.065)\end{array}$ & $\begin{array}{c}-0.544^{* * *} \\
(0.078)\end{array}$ & $\begin{array}{c}-0.538 * * * \\
(0.068)\end{array}$ & $\begin{array}{c}-0.531^{* * *} \\
(0.066)\end{array}$ \\
\hline SPREAD & - & $\begin{array}{c}-0.214^{* * *} \\
(0.063)\end{array}$ & $\begin{array}{c}-0.233^{* * *} \\
(0.062)\end{array}$ & $\begin{array}{c}-0.337^{* * *} \\
(0.074)\end{array}$ & $\begin{array}{c}-0.332 * * * \\
(0.081)\end{array}$ & $\begin{array}{c}-0.335^{* * *} \\
(0.076)\end{array}$ & $\begin{array}{c}-0.338^{* * *} \\
(0.075)\end{array}$ \\
\hline TRADE & - & - & $\begin{array}{l}0.179^{*} \\
(0.106)\end{array}$ & $\begin{array}{c}0.309 * * * \\
(0.100)\end{array}$ & $\begin{array}{c}0.302 * * * \\
(0.100)\end{array}$ & $\begin{array}{c}0.306^{* * *} \\
(0.102)\end{array}$ & $\begin{array}{c}0.309^{* * *} \\
(0.098)\end{array}$ \\
\hline URBAN & - & - & - & $\begin{array}{c}-0.233^{* * *} \\
(0.071)\end{array}$ & $\begin{array}{c}-0.238 * * * \\
(0.073)\end{array}$ & $\begin{array}{c}0.235^{* * *} \\
(0.073)\end{array}$ & $\begin{array}{c}-0.232 * * * \\
(0.072)\end{array}$ \\
\hline R-squared & 0.560 & 0.592 & 0.600 & 0.626 & 0.626 & 0.626 & 0.626 \\
\hline Adj. R-squared & 0.546 & 0.577 & 0.583 & 0.608 & - & - & - \\
\hline Hetero & $4.634[0.000]$ & $7.896[0.000]$ & $7.525[0.000]$ & $7.365[0.000]$ & $6.924[0.000]$ & $7.159[0.000]$ & $7.419[0.000]$ \\
\hline Reset2 & $1.870[0.173]$ & $12.040[0.000]$ & $8.350[0.004]$ & $11.750[0.000]$ & $10.820[0.001]$ & n.a. & n.a. \\
\hline Reset23 & $11.970[0.000]$ & $9.710[0.000]$ & $8.390[0.000]$ & $7.870[0.000]$ & $8.010[0.000]$ & n.a. & n.a. \\
\hline Normality & $0.062[0.96]$ & $3.080[0.214]$ & $3.641[0.162]$ & $5.269[0.072]$ & $4.541[0.103]$ & $4.930[0.085]$ & $5.358[0.069]$ \\
\hline Underidentification & - & - & - & - & $\begin{array}{l}18.760 \\
{[0.004]} \\
22.435\end{array}$ & $\begin{array}{l}15.882 \\
{[0.026]} \\
30.459\end{array}$ & $\begin{array}{l}33.730 \\
{[0.001]} \\
52.992\end{array}$ \\
\hline Hansen J & - & - & - & - & $\begin{array}{c}{[0.000]} \\
5.946 \\
{[0.015]}\end{array}$ & 2.234 [0.135] & $\begin{array}{c}{[0.000]} \\
3.785 \\
{[0.052]}\end{array}$ \\
\hline Obs & 171 & 171 & 171 & 171 & 171 & 171 & 171 \\
\hline
\end{tabular}

The Table reports the results of stacked OLS (columns 1-4) and GMM (columns 5-7) estimation for the linear model, with robust standard errors in round brackets. Income inequality is measured by the stacked market $(G M)$ and net (GN and $G W$ ) income Gini Index, while financial development $f$ by the stacked GDP shares of credit to the private sector $(c)$, liquid liabilities $(m)$ and stock market capitalization (s). The other (stacked) regressors are: $x g$, the product of trend real per capita income at mid sample (year-2000) value $(x)$ and its average rate of growth over the 1985-2013 period $(\mathrm{g})$, $\mathrm{fg}$, the product of the trend financial development index at mid-sample (year 2000) value $(f)$ and the trend per capita income average rate of growth $(g)$, and the (average over the 1985-2013 period) age dependency ratio $(D E P)$, government spending $(P E)$, population share living in urban area (URB), trade openness (TRADE) and 10year Treasury bond rate spread relatively to the German T-Bund rate (SPREAD). Results of GMM estimation performed using La Porta et al. (1997) and Lewbel (2012) instruments for the interacted financial development variable $f g$ are reported in columns 5 and 6 , respectively; GMM results in column 7 refer to the case in which La Porta et al. (1997) and Lewbel (2012) instruments are employed jointly. R-squared and Adj. R-squared are the unadjusted and adjusted coefficient of determination; Hetero is the White test for heteroscedasticity; Reset2 and Reset23 are the Ramsey-Reset functional form tests using squares and squares and cubes of fitted values, respectively; Normality is the Bera-Jarque Normality test; Underidentification is the Kleibergen-Paap rk underidentification test; Hansen $\mathrm{J}$ is the Sargan-Hansen instruments validity test; Exogeneity is the Hausman test for the weak exogeneity of the interacted financial development variable $f g$. P-values are reported in square brackets. The symbols *, **, *** denotes significance at 10, 5 and 1 per cent level, respectively. The number of observations is denoted by Obs. 
Table 2: Stacked OLS and GMM (M.A.S.) estimation results for the log-log model

\begin{tabular}{|c|c|c|c|c|c|c|c|}
\hline & $\begin{array}{l}(1) \\
\text { OLS }\end{array}$ & $\begin{array}{l}(2) \\
\text { OLS }\end{array}$ & $\begin{array}{l}(3) \\
\text { OLS }\end{array}$ & $\begin{array}{l}(4) \\
\text { OLS }\end{array}$ & $\begin{array}{c}\text { (5) } \\
\text { GMM }\end{array}$ & $\begin{array}{c}(\mathbf{6}) \\
\text { GMM }\end{array}$ & $\begin{array}{c}(7) \\
\text { GMM }\end{array}$ \\
\hline$x g$ & $\begin{array}{c}-0.226^{* * *} \\
(0.039)\end{array}$ & $\begin{array}{c}-0.274^{* * *} \\
(0.042)\end{array}$ & $\begin{array}{c}-0.269 * * * \\
(0.044)\end{array}$ & $\begin{array}{c}-0.254^{* * *} \\
(0.042)\end{array}$ & $\begin{array}{c}-0.211^{* * *} \\
(0.077)\end{array}$ & $\begin{array}{c}-0.211^{* * *} \\
(0.059)\end{array}$ & $\begin{array}{c}-0.254^{* * *} \\
(0.049)\end{array}$ \\
\hline$g$ & $\begin{array}{l}-0.054 \\
(0.051)\end{array}$ & $\begin{array}{l}-0.070 \\
(0.052)\end{array}$ & $\begin{array}{l}-0.057 \\
(0.073)\end{array}$ & $\begin{array}{l}-0.106 \\
(0.084)\end{array}$ & $\begin{array}{l}-0.032 \\
(0.043)\end{array}$ & $\begin{array}{l}-0.032 \\
(0.063)\end{array}$ & $\begin{array}{l}-0.058 \\
(0.050)\end{array}$ \\
\hline$f g$ & $\begin{array}{c}-0.289^{* * *} \\
(0.066)\end{array}$ & $\begin{array}{c}-0.243^{* * *} \\
(0.070)\end{array}$ & $\begin{array}{c}-0.244^{* * *} \\
(0.071)\end{array}$ & $\begin{array}{c}-0.252^{* * *} \\
(0.069)\end{array}$ & $\begin{array}{c}-0.379 * * * \\
(0.116)\end{array}$ & $\begin{array}{c}-0.379 * * * \\
(0.141)\end{array}$ & $\begin{array}{c}-0.286^{* * *} \\
(0.077)\end{array}$ \\
\hline$D E P$ & $\begin{array}{c}0.620^{* * *} \\
(0.054)\end{array}$ & $\begin{array}{c}0.501^{* * *} \\
(0.045)\end{array}$ & $\begin{array}{c}0.499 * * * \\
(0.047)\end{array}$ & $\begin{array}{c}0.492 * * * \\
(0.050)\end{array}$ & $\begin{array}{c}0.527^{* * *} \\
(0.039)\end{array}$ & $\begin{array}{c}0.526^{* * *} \\
(0.059)\end{array}$ & $\begin{array}{c}0.509^{* * *} \\
(0.046)\end{array}$ \\
\hline$P E$ & $\begin{array}{c}-0.444^{* * * *} \\
(0.066)\end{array}$ & $\begin{array}{c}-0.460^{* * * *} \\
(0.061)\end{array}$ & $\begin{array}{c}-0.457 * * * \\
(0.059)\end{array}$ & $\begin{array}{c}-0.439 * * * \\
(0.061)\end{array}$ & $\begin{array}{c}-0.508^{* * *} \\
(0.059)\end{array}$ & $\begin{array}{c}-0.508^{* * *} \\
(0.089)\end{array}$ & $\begin{array}{c}-0.475^{* * *} \\
(0.064)\end{array}$ \\
\hline SPREAD & - & $\begin{array}{c}-0.237 * * * \\
(0.058)\end{array}$ & $\begin{array}{c}-0.236^{* * *} \\
(0.058)\end{array}$ & $\begin{array}{c}-0.289 * * * \\
(0.073)\end{array}$ & $\begin{array}{c}-0.222 * * * \\
(0.061)\end{array}$ & $\begin{array}{c}-0.222 * * * \\
(0.062)\end{array}$ & $\begin{array}{c}-0.232 * * * \\
(0.060)\end{array}$ \\
\hline TRADE & - & - & $\begin{array}{c}-0.019 \\
(0.070)\end{array}$ & $\begin{array}{c}0.022 \\
(0.077)\end{array}$ & - & - & - \\
\hline URBAN & - & - & - & $\begin{array}{l}-0.102 \\
(0.072)\end{array}$ & - & - & - \\
\hline R-squared & 0.593 & 0.634 & 0.634 & 0.639 & 0.626 & 0.626 & 0.633 \\
\hline Adj. R-squared & 0.580 & 0.620 & 0.618 & 0.621 & - & - & - \\
\hline Hetero & $4.605[0.000]$ & $8.182[0.000]$ & $8.000[0.000]$ & $12.219[0.000]$ & $7.103[0.000]$ & $7.100[0.000]$ & $7.844[0.000]$ \\
\hline Reset2 & $1.020[0.315]$ & $0.010[0.918]$ & $0.000[0.962]$ & $0.010[0.916]$ & $0.830[0.363]$ & n.a. & n.a. \\
\hline Reset23 & $9.120[0.000]$ & $7.520[0.000]$ & $8.740[0.000]$ & $7.010[0.001]$ & $0.680[0.509]$ & n.a. & n.a. \\
\hline Normality & $0.977[0.610]$ & $2.725[0.256]$ & $2.179[0.336]$ & $2.537[0.281]$ & $5.296[0.071]$ & $5.307[0.070]$ & $3.384[0.184]$ \\
\hline Underidentification & - & - & - & - & $34.903[0.000]$ & $19.388[0.001]$ & $55.225[0.000]$ \\
\hline Hansen $\mathrm{J}$ & - & - & - & - & $15.384[0.009]$ & $8.024[0.091]$ & $23.471[0.009]$ \\
\hline Exogeneity & - & - & - & - & $1.857[0.173]$ & $0.795[0.372]$ & $0.142[0.706]$ \\
\hline Obs & 171 & 171 & 171 & 171 & 171 & 171 & 171 \\
\hline
\end{tabular}

The Table reports the results of stacked OLS (columns 1-4) and GMM (columns 5-7) estimation for the log-log model, with robust standard errors in round brackets. Income inequality is measured by the stacked market $(G M)$ and net $(G N$ and $G W)$ income Gini Index, while financial development $f$ by the stacked GDP shares of credit to the private sector $(c)$, liquid liabilities $(m)$ and stock market capitalization (s). The other (stacked) regressors are: $x g$, the product of trend real per capita income at mid sample (year-2000) value $(x)$ and its average rate of growth over the 1985-2013 period $(\mathrm{g})$; $\mathrm{fg}$, the product of the trend financial development index at mid-sample (year 2000) value $(f)$ and the trend per capita income average rate of growth $(g)$; the (average over the 1985-2013 period) age dependency ratio $(D E P)$, government spending $(P E)$, population share living in urban area $(U R B)$, trade openness (TRADE) and 10year Treasury bond rate spread relatively to the German T-Bund rate (SPREAD). Results of GMM estimation performed using La Porta et al. (1997) and Lewbel (2012) instruments for the interacted financial development variable $f g$ are reported in columns 5 and 6 , respectively; GMM results in column 7 refer to the case in which La Porta et al. (1997) and Lewbel (2012) instruments are employed jointly. $R$-squared and Adj. R-squared are the unadjusted and adjusted coefficient of determination; Hetero is the White test for heteroscedasticity; Reset2 and Reset23 are the Ramsey-Reset functional form tests using squares and squares and cubes of fitted values, respectively; Normality is the Bera-Jarque Normality test; Underidentification is the Kleibergen-Paap rk underidentification test; Hansen $\mathrm{J}$ is the Sargan-Hansen instruments validity test; Exogeneity is the Hausman test for the weak exogeneity of the interacted financial development variable $f g$. P-values are reported in square brackets. The symbols *, **, *** denotes significance at 10, 5 and 1 per cent level, respectively. The number of observations is denoted by Obs. 
Table 3: EA-wide Steady-state financial Kuznets curve: turning point real per capita income and inequality and reference level for financial development

\begin{tabular}{|c|c|c|c|c|c|}
\hline \multicolumn{6}{|c|}{ Linear model } \\
\hline & $\hat{\boldsymbol{x}}^{*}$ & $\hat{y}_{G N}^{*}$ & $\hat{y}_{G W}^{*}$ & $\hat{y}_{G M}^{*}$ & $\hat{\boldsymbol{f}}^{*}$ \\
\hline$O L S$ & 11771 & 30.121 & 31.277 & 47.631 & 82.150 \\
\hline$G M M$ & 11595 & 30.083 & 31.287 & 47.564 & 82.150 \\
\hline$M I X$ & 11683 & 30.106 & 31.262 & 47.616 & 82.150 \\
\hline \multicolumn{6}{|c|}{ Log-log model } \\
\hline & $\hat{\boldsymbol{x}}^{*}$ & $\hat{y}_{G N}^{*}$ & $\hat{y}_{G W}^{*}$ & $\hat{y}_{G M}^{*}$ & $\hat{\boldsymbol{f}}^{*}$ \\
\hline \multirow{2}{*}{ OLS } & 13279 & 31.024 & 32.215 & 48.498 & 82.150 \\
\hline & (1207) & $(0.446)$ & (2.005) & $(0.434)$ & \\
\hline$G M M$ & 14327 & 30.789 & 26.834 & 48.272 & 82.150 \\
\hline$M I X$ & 13973 & 30.904 & 32.090 & 48.382 & 82.150 \\
\hline
\end{tabular}

The Table reports EA-wide financial Kuznets curve turning point per capita income $\left(\hat{x}^{*}\right)$ and Gini Index income inequality $\left(\hat{y}_{i}^{*} ; i=\right.$ $G N, G W, G M)$, obtained by means of the linear and log-log models and the OLS, GMM and MIX estimators. The reported reference level for financial development $\left(\hat{f}^{*}\right)$ is the across-country average of the trend financial development index at mid-sample (year 2000) value. The sample standard deviation of the various turning points, obtained by the linear and log-log specifications and the OLS, GMM and MIX estimators, is reported in round brackets, below the selected OLS log-log model estimates. 
Table 4: EA own-country steady-state financial Kuznets curve for $D E V$ and $U D V$ countries: turning point real per capita income and inequality and reference level for financial development

\begin{tabular}{c|ccccc}
\hline & $\hat{\boldsymbol{x}}^{*}$ & $\hat{\boldsymbol{y}}_{G N}^{*}$ & $\hat{\boldsymbol{y}}_{G W}^{*}$ & $\hat{\boldsymbol{y}}_{G M}^{*}$ & $\hat{\boldsymbol{f}}^{*}$ \\
\hline $\boldsymbol{D E \boldsymbol { V }}$ & & & & & \\
$\boldsymbol{e} \boldsymbol{X}-\boldsymbol{N L}$ & 9991 & 33.011 & 34.921 & 54.055 & 95.471 \\
$\boldsymbol{a l l}$ & 12156 & 32.450 & 34.346 & 53.351 & 91.573 \\
$\boldsymbol{U D V}$ & & & & & \\
$\boldsymbol{e} \boldsymbol{X}-\boldsymbol{L T}$ & 16236 & 33.418 & 32.515 & 53.338 & 72.285 \\
$\boldsymbol{a l l}$ & 21140 & 35.205 & 34.378 & 55.557 & 65.989 \\
\hline
\end{tabular}

The Table reports the own-country EA financial Kuznets curve turning point per capita income $\left(\hat{\boldsymbol{x}}^{*}\right)$ and Gini Index income inequality $\left(\hat{y}_{i}^{*} ; i=G N, G W, G M\right)$, obtained by means of the selected log-log model and OLS estimator, for the two groups of more developed $(D E V)$ and less developed (UDV) countries. In the Table two sets of results are reported; the first set refers to the case in which all the countries belonging to each group are considered (all); the second set refers to the case in which the outlying countries, i.e., the Netherlands and Lithuania, are excluded from the corresponding group, respectively (ex- $N L ; e x-L T)$. The reported reference level for financial development $\left(\hat{f}^{*}\right)$ is computed as the across-country average of the trend financial development index at mid-sample (year 2000) value for each group. Finally, DEV: Austria, Belgium, Finland, France, Germany, Greece, Ireland, Italy, Luxemburg, Portugal, Spain, the Netherlands; UDV: Cyprus, Estonia, Latvia, Lithuania, Malta, Slovakia and Slovenia. 
Table 5: Real per capita income, financial development and Gini Index anomaly and actual values: 2008-2013

Panel A: EA member country figures

\begin{tabular}{|c|c|c|c|c|c|c|c|c|c|c|c|c|c|}
\hline & \multicolumn{2}{|c|}{$\begin{array}{c}\text { Real per capita } \\
\text { income }\end{array}$} & \multicolumn{2}{|c|}{$\begin{array}{c}\begin{array}{c}\text { Financial } \\
\text { development }\end{array} \\
\end{array}$} & \multicolumn{6}{|c|}{ Actual Gini Index } & \multicolumn{3}{|c|}{ Gini Index Anomaly } \\
\hline & $x$ & $x_{\%}$ & $f$ & $\boldsymbol{f}_{\%}$ & $G N$ & $G \boldsymbol{N}_{\%}$ & $G W$ & $G W_{\%}$ & $G M$ & $G M_{\%}$ & $G N_{a}$ & $G W_{a}$ & $G M_{a}$ \\
\hline Austria & 32761 & 0.3 & 103.62 & -9.89 & 27.66 & 2.85 & 26.48 & 1.08 & 46.34 & 0.97 & 2.688 & 2.38 & 5.756 \\
\hline Belgium & 30389 & -1.83 & 110.79 & -13.96 & 25.47 & -1.19 & 26.7 & 1.5 & 44.57 & 3.41 & 2.33 & 1.826 & 1.921 \\
\hline Finland & 32192 & -5.37 & 90.05 & -2.37 & 26.18 & -0.83 & 25.78 & -1.59 & 47.57 & 1.64 & 5.695 & 4.67 & 6.943 \\
\hline France & 28550 & -1.58 & 103.26 & -6.7 & 29.45 & 5.78 & 30.18 & 13.47 & 49.49 & 2 & 2.191 & 2.977 & 1.912 \\
\hline Germany & 30475 & 1.87 & 99.07 & -4.63 & 28.64 & -0.57 & 29.12 & -4.22 & 50.87 & 0.35 & 2.678 & 4.081 & 6.706 \\
\hline Greece & 16901 & -13.53 & 106.03 & -7.76 & 33.18 & 4.34 & 33.62 & -1.98 & 50.79 & 6.03 & 0.79 & 0.558 & 5.413 \\
\hline Ireland & 38305 & -9.99 & 143.09 & -18.99 & 29.21 & -1.65 & 29.83 & -4.69 & 54.15 & 8.52 & -0.624 & -0.019 & 7.288 \\
\hline Italy & 24617 & -6.75 & 101.98 & -5.1 & 32.67 & -1.05 & 31.9 & 2.9 & 48.84 & -0.05 & 1.166 & 0.994 & 4.097 \\
\hline Luxemburg & 65231 & -5.81 & 121.04 & -23.87 & 27.04 & -2.04 & 27.92 & 1.89 & 46.15 & 0.55 & 2.861 & 1.979 & 7.461 \\
\hline Spain & 20973 & -5.71 & 139.16 & -3.44 & 32.83 & 7.29 & 33.75 & 5.8 & 49.97 & 11.3 & 3.779 & 5.71 & 9.354 \\
\hline Portugal & 15160 & -3.21 & 127.72 & -6.48 & 34 & -3.57 & 34.72 & -5.64 & 56.08 & -0.92 & 4.211 & -0.44 & 8.031 \\
\hline Netherlands & 35204 & -1.4 & 51.49 & -15.29 & 25.75 & -6.01 & 26.14 & -5.28 & 45.52 & -1.9 & -0.545 & -2.197 & -0.274 \\
\hline Slovakia & 11891 & 5.83 & 78.91 & -33.04 & 26.17 & 5.53 & 25.34 & 3.41 & 42.82 & 2.94 & -0.602 & -1.571 & -2.804 \\
\hline Slovenia & 15599 & -4.67 & 109.1 & -11.54 & 24.77 & 7.68 & 23.7 & 2.14 & 41.14 & 3.9 & 5.333 & 2.835 & 9.229 \\
\hline Estonia & 9033 & -9.72 & 81.03 & -7.13 & 32.35 & 1.59 & 31.72 & -5.02 & 48.87 & 5.49 & -3.535 & -3.521 & -3.054 \\
\hline Latvia & 3554 & -10.03 & 78.18 & 29.11 & 35.49 & -2.41 & 36.15 & 2.12 & 56.7 & -2.89 & -3.201 & -1.658 & -5.355 \\
\hline Cyprus & 15467 & -4.4 & 138.13 & -11.66 & 29.98 & 1.91 & 29.27 & -1.79 & 48.83 & 2.03 & 7.15 & 5.577 & 8.228 \\
\hline Malta & 13089 & 3.66 & 73.03 & -11.28 & 27.39 & 0.92 & 27.62 & 5.01 & 44.98 & 0.9 & -1.285 & -1.424 & -2.14 \\
\hline Lithuania & 7102 & 0.49 & 40.55 & -19.47 & 34.65 & -0.8 & 34.33 & -1.9 & 54.83 & -0.86 & -2.099 & -3.616 & -2.482 \\
\hline
\end{tabular}

Panel B: Average figures

\begin{tabular}{|c|c|c|c|c|c|c|c|c|c|c|c|c|c|}
\hline & \multicolumn{2}{|c|}{$\begin{array}{c}\text { Real per capita } \\
\text { income }\end{array}$} & \multicolumn{2}{|c|}{$\begin{array}{c}\begin{array}{c}\text { Financial } \\
\text { development }\end{array} \\
\end{array}$} & \multicolumn{6}{|c|}{ Actual Gini Index } & \multicolumn{3}{|c|}{ Gini Index Anomaly } \\
\hline & $\boldsymbol{x}$ & $\boldsymbol{x}_{\%}$ & $f$ & $\boldsymbol{f}_{\%}$ & $G N$ & $G \boldsymbol{N}_{\%}$ & $G W$ & $G W_{\%}$ & $G M$ & $G \boldsymbol{M}_{\%}$ & $G N_{a}$ & $G W_{a}$ & $G M_{a}$ \\
\hline Average EA & 23500 & -3.782 & 99.802 & -9.657 & 29.625 & 0.935 & 29.698 & 0.379 & 48.869 & 2.285 & 1.525 & 1.008 & 3.486 \\
\hline DSFKC & 28201 & -4.668 & 114.849 & -9.722 & 29.314 & 1.458 & 29.459 & 0.682 & 48.83 & 3.056 & 3.096 & 2.548 & 6.334 \\
\hline USFKC & 8934 & -1.954 & 70.34 & -8.362 & 31.21 & 0.966 & 31.032 & 0.724 & 49.64 & 1.116 & -2.144 & -2.358 & -3.167 \\
\hline
\end{tabular}

Panel A reports average figures for EA member countries Gini Index anomaly $\left(G N_{a}, G W_{a}, G M_{a}\right)$ and actual values, in levels $(G N, G W, G M)$ and rate of growth $\left(G N_{\%}, G W_{\%}, G M_{\%}\right)$, over the period 2008-2013. Figures for the 2008-2013 average trend per capita income and financial development levels $(x, f)$ and rates of growth $\left(x_{\%}, f_{\%}\right)$ are also reported. Panel B reports EA-wide average figures, for all the EA countries (EA-wide) and the two groups with downward (DSFKC) and upward (USFKC) sloped financial Kuznets curves, respectively. DSFKC: Austria, Belgium, Finland, France, Germany, Greece, Ireland, Italy, Luxemburg, Spain, Portugal, as well as Cyprus and Slovenia; USFKC: Estonia, Latvia, Lithuania, Malta, Slovakia. The outlying figures for the Netherlands are neglected in the computations for USFKC. 

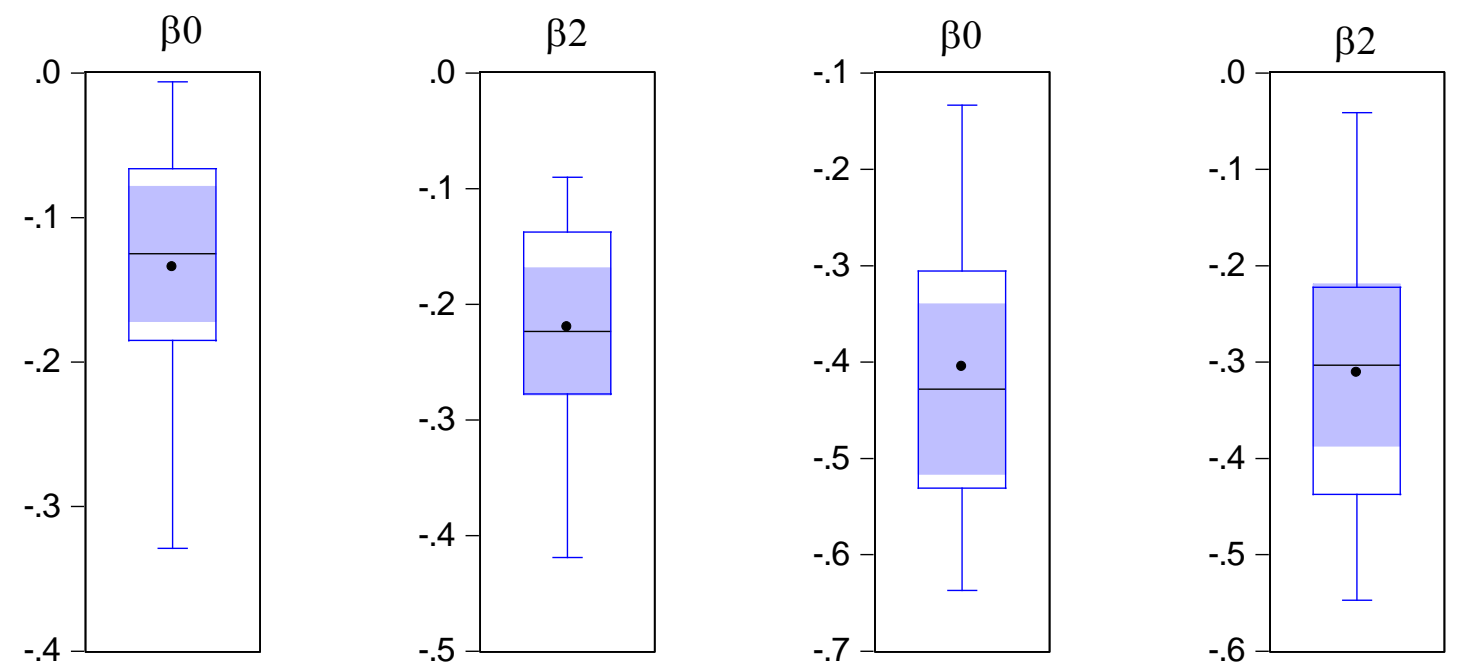

LINEAR MODEL

LOG-LOG MODEL

Figure 1: In the Figure box-plots for the estimated $\beta_{0}$ and $\beta_{2}$ parameters from the linear and log-log crosssectional regressions are reported. The box portion represents the first and third quartiles, while the median is depicted using a line through the center of the box and the mean is drawn using the dot. The difference between the first and third quartiles represents the interquartile range, or IQR. The shaded areas refer to the 95\% confidence interval about the median, while the outer lines represent the last data point within (or equal to) each of the inner fences, defined as the first quartile minus $1.5 * \mathrm{IQR}$ and the third quartile plus $1.5^{*} \mathrm{IQR}$. 


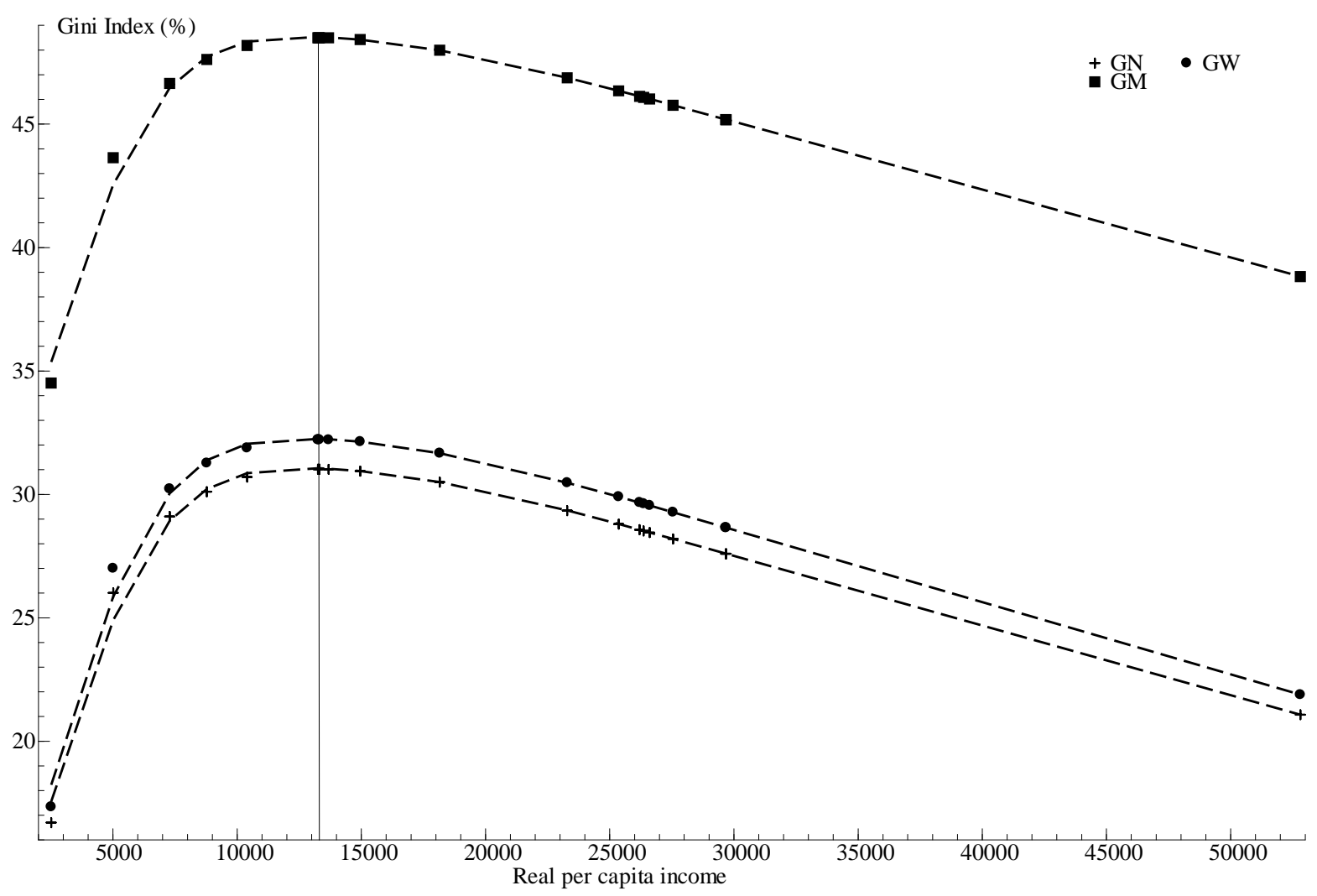

Figure 2: In the plot the estimated EA steady-state financial Kuznets curve (cubic spline interpolation), obtained by means of the preferred OLS log-log model, is plotted with reference to the available three measures of income inequality, i.e., the net (GN) and market (GM) income Gini Index (\%), as yield by the Standardized World Income Inequality Database (SWIID), and the net income (GW) Gini index (\%), as yield by the World Income Inequality Database (WIID). Real per capita income is measured by mid-sample (year 2000) trend figures. 


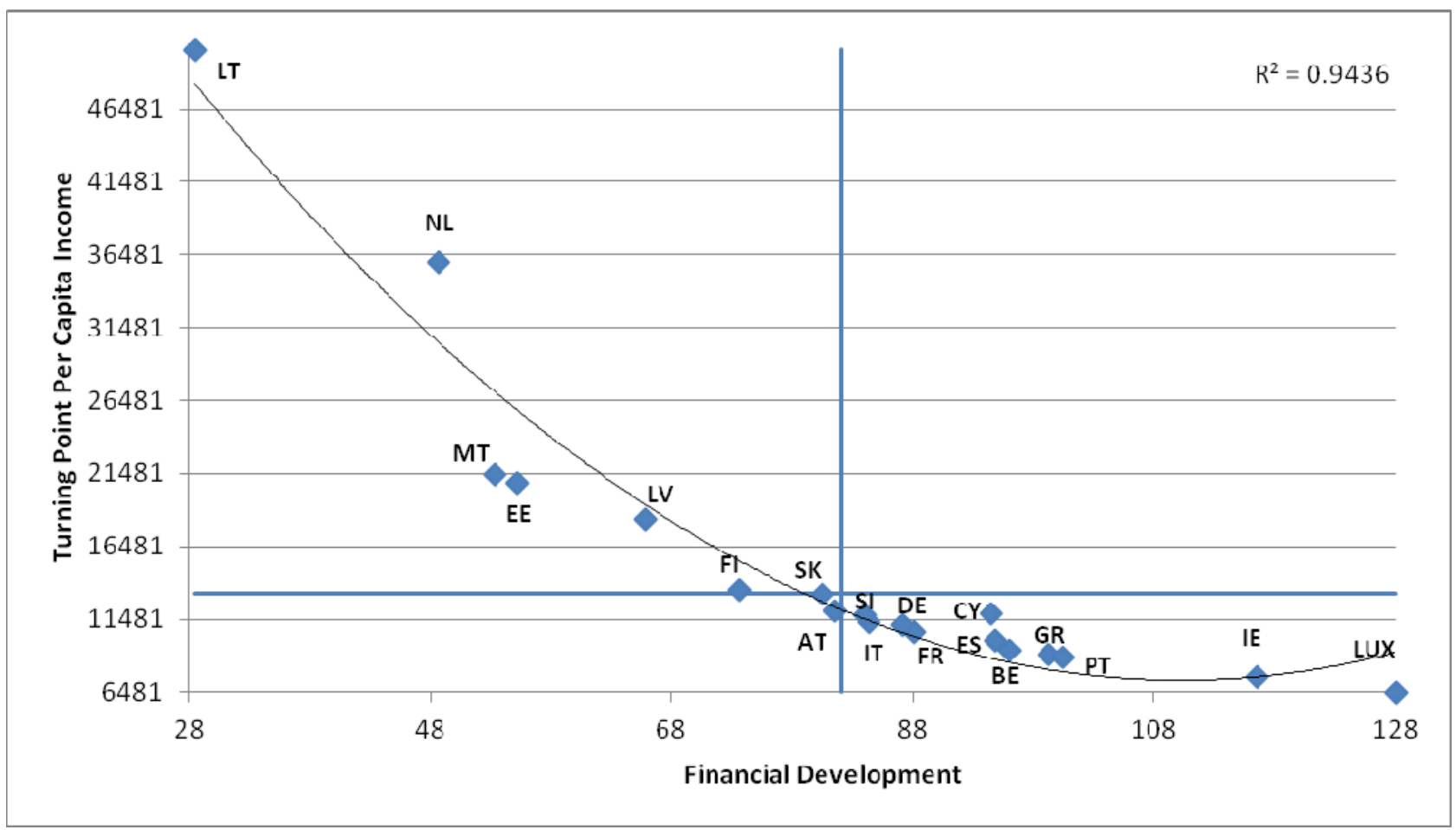

Figure 3: The plot shows the relationship between the selected OLS log-log model estimates of the EA member country FKC turning point real per capita income level $\left(\mathrm{x}^{*}\right)$ and the level of financial development $(f)$, as measured by the average of trend GDP shares of credit to the private sector, liquid liabilities and stock market capitalization at mid sample (year 2000) values. The straight lines are reported in correspondence of the estimated values for the EA steady-state Kuznets curve. 

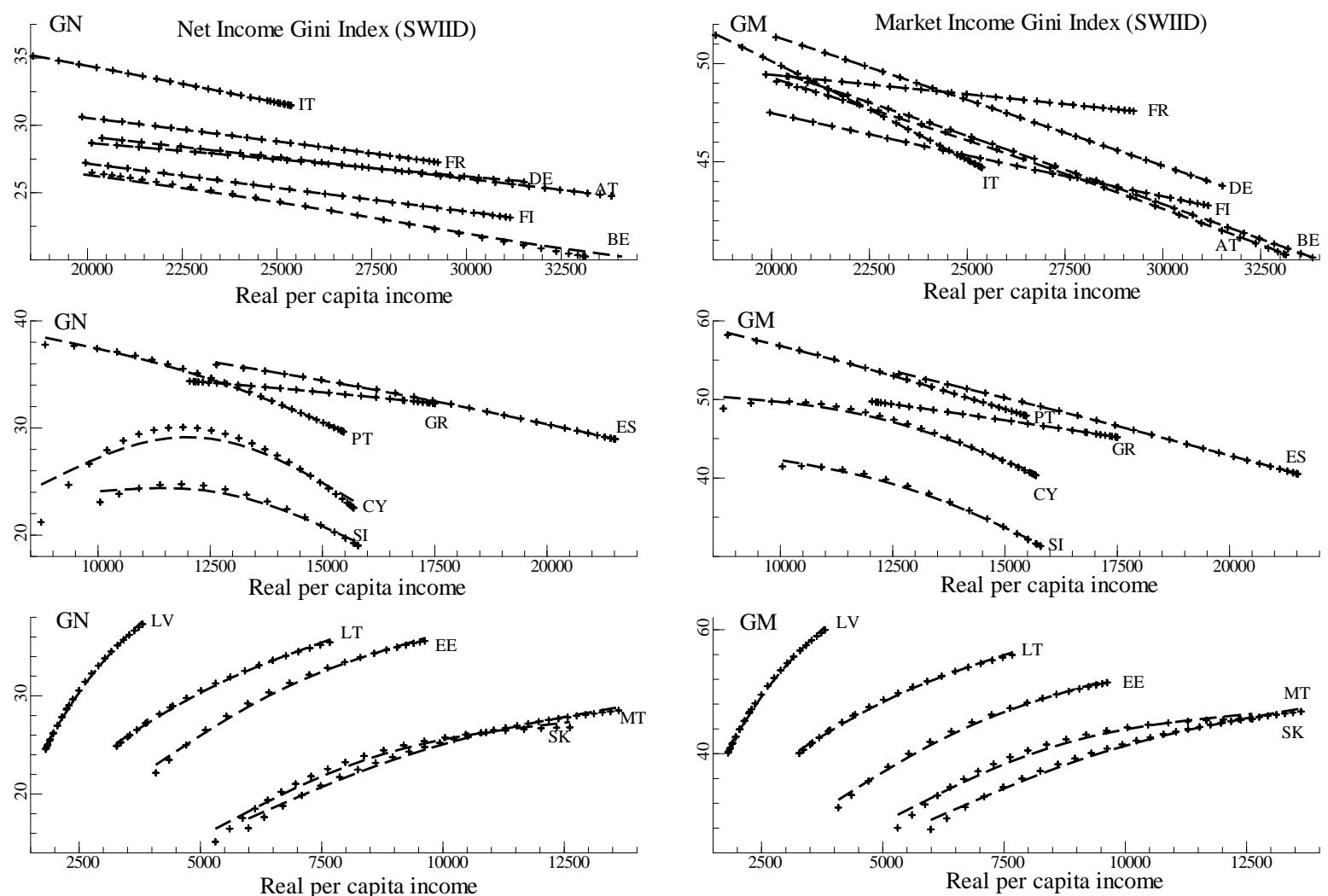

Figure 4: In the plot the estimated financial Kuznets curve for the various EA countries, obtained by means of the preferred OLS log-log model, are plotted with reference to the net (GN) and market (GM) income Gini Index (\%), as yield by the Standardized World Income Inequality Database (SWIID). Real per capita income is measured by trend figures over the period 1985 through 2013. Figures for Ireland, the Netherlands and Luxemburg are not reported for graphical convenience. 

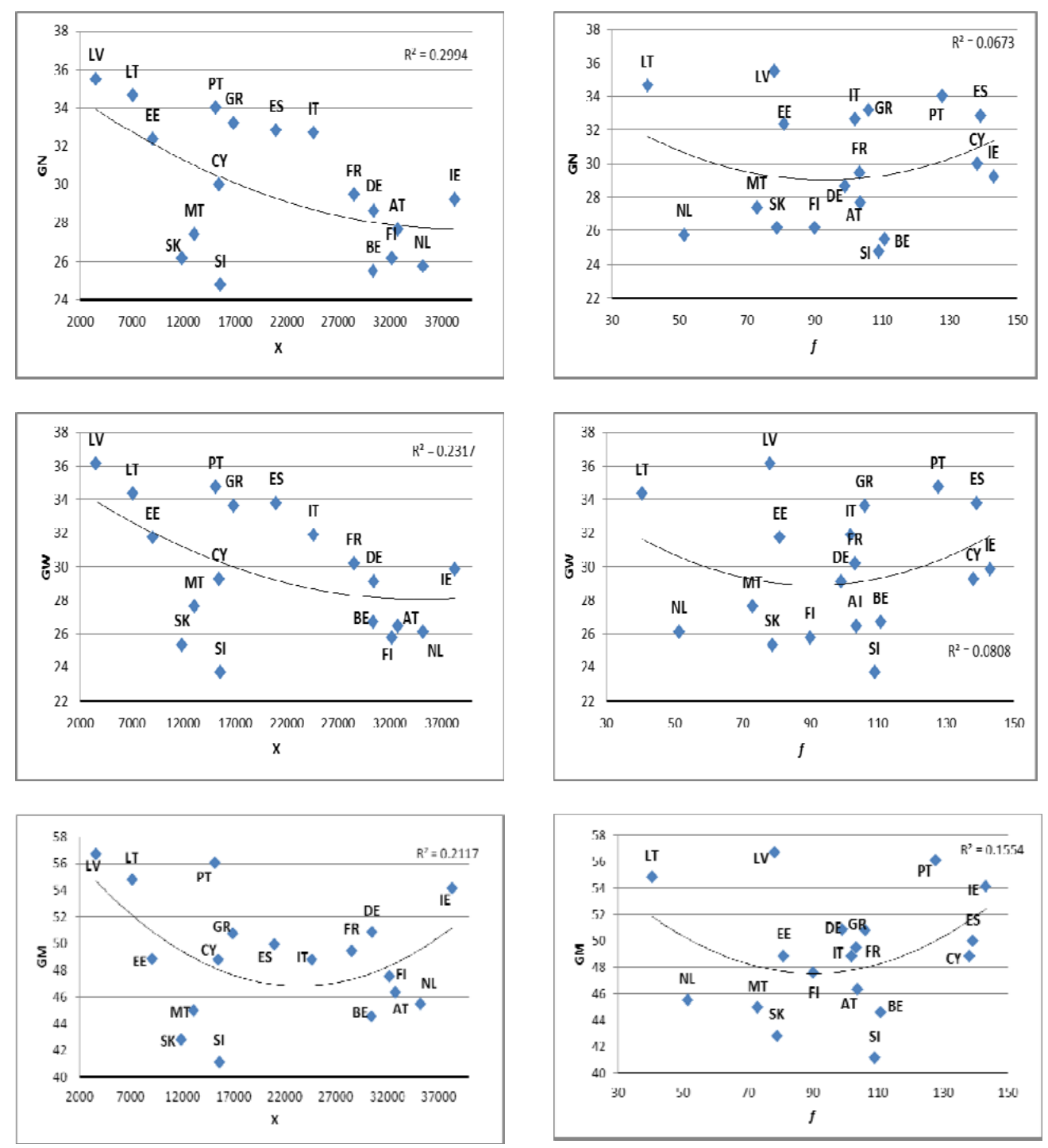
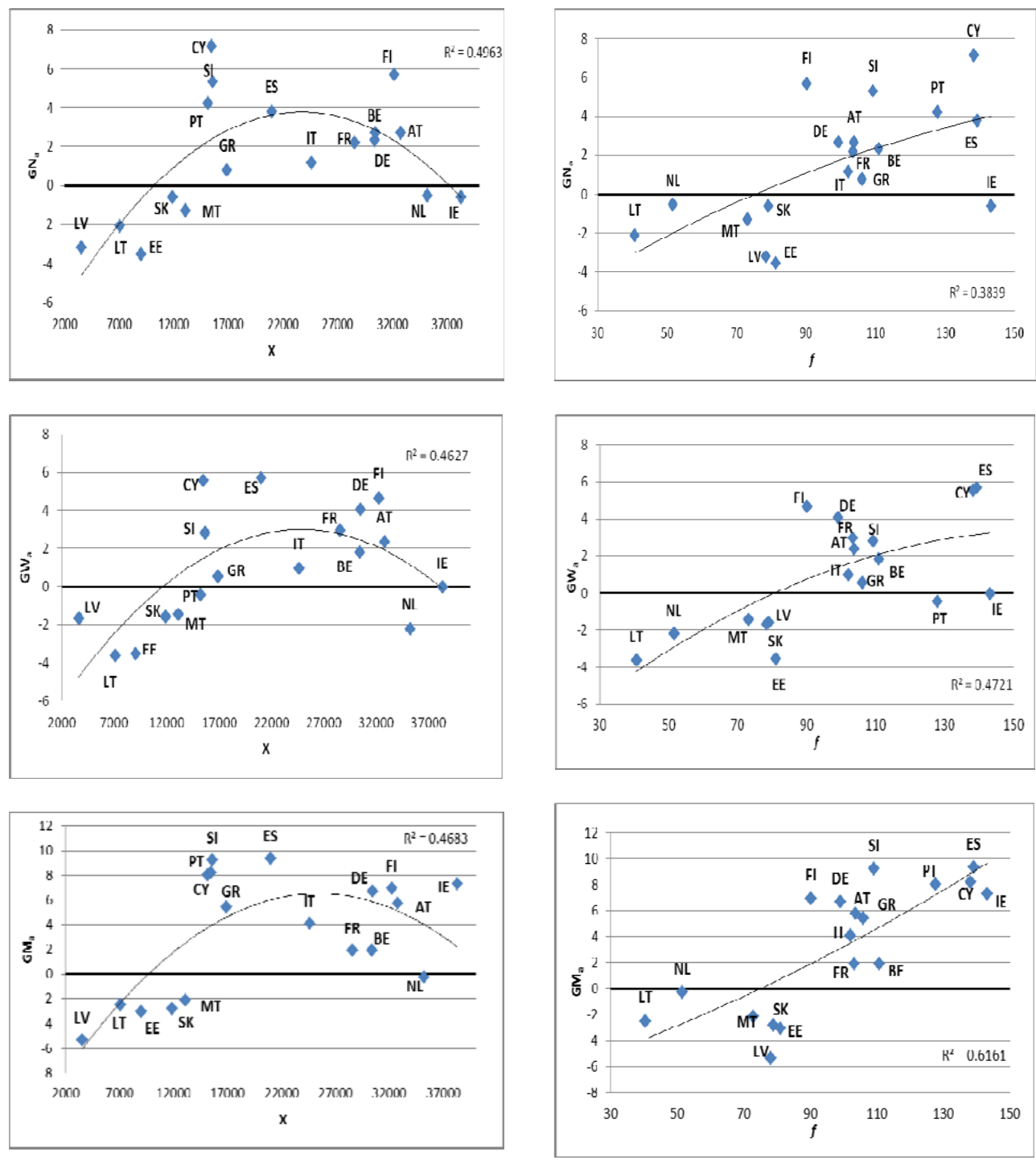

Figure 5: Gini Index levels $(G N, G W, G M)$ and corresponding anomaly values $\left(G N_{a}, G W_{a}, G M_{a}\right)$ versus real per capita income $(x)$ and financial development $(f)$. Figures for Luxemburg are omitted for graphical convenience. 